NBER WORKING PAPER SERIES

\title{
MEASURING THE EFFECTS OF FEDERAL RESERVE FORWARD GUIDANCE AND ASSET PURCHASES ON FINANCIAL MARKETS
}

\author{
Eric T. Swanson \\ Working Paper 23311 \\ http://www.nber.org/papers/w23311 \\ NATIONAL BUREAU OF ECONOMIC RESEARCH \\ 1050 Massachusetts Avenue \\ Cambridge, MA 02138 \\ April 2017
}

I thank Mike Woodford for encouraging me to start this project, and Sof'a Bauducco, Joe Gagnon, SungJun Huh, Youngseung Jung, Don Kim, Ken Kuttner, Pascal Paul, Matt Roberts-Sklar, Alexandre Ziegler, and seminar participants at the Banca d'Italia, Banque de France, Boston College, Cal State Fullerton, the Federal Reserve Banks of Boston, Chicago, and Kansas City, London School of Economics, National Bank of Belgium, Norges Bank, Swiss National Bank, UC Irvine, UC Riverside, UC Santa Cruz, University of Southern California, University of Zurich, the California Macroeconomics Conference, Central Bank of Chile Annual Conference, Federal Reserve Board Conference on Empirical Monetary Economics, Joint Conference of the Korean Economic Association and Social Science Korea Research Team, NBER Summer Institute Forecasting and Empirical Methods and Monetary Economics Workshops, Society for Computational Economics, Society for Economic Dynamics, and EABCN Conference on Unconventional Monetary Policy for helpful discussions, comments, and suggestions. Earlier work on this project was supported in part by the Central Bank of Chile. The views expressed in this paper, and all errors and omissions, are my own and are not necessarily those of the individuals or groups listed above, nor of the National Bureau of Economic Research.

NBER working papers are circulated for discussion and comment purposes. They have not been peerreviewed or been subject to the review by the NBER Board of Directors that accompanies official NBER publications.

(C) 2017 by Eric T. Swanson. All rights reserved. Short sections of text, not to exceed two paragraphs, may be quoted without explicit permission provided that full credit, including $\odot$ notice, is given to the source. 
Measuring the Effects of Federal Reserve Forward Guidance and Asset Purchases on Financial Markets

Eric T. Swanson

NBER Working Paper No. 23311

April 2017, Revised August 2018

JEL No. E44,E52,E58

\begin{abstract}
$\underline{\text { ABSTRACT }}$
I extend the methods of G"urkaynak, Sack, and Swanson (2005) to separately identify the effects of Federal Reserve forward guidance and large-scale asset purchases (LSAPs) during the 2009-15 U.S. zero lower bound (ZLB) period. I find that both forward guidance and LSAPs had substantial and highly statistically significant effects, comparable in magnitude to the effects of the federal funds rate before the ZLB. Forward guidance was more effective than LSAPs at moving short-term Treasury yields, while LSAPs were more effective than forward guidance and the federal funds rate at moving longer-term Treasury and corporate bond yields. I estimate that the effects of LSAP announcements were very persistent, with the exception of the very large and perhaps special March 2009 "QE1" announcement. The effects of forward guidance are slightly less persistent, but the difference is not statistically significant and is likely due to the FOMC's forward guidance announcements having a relatively shorter horizon.
\end{abstract}

Eric T. Swanson

Department of Economics

University of California at Irvine

3151 Social Science Plaza

Irvine, CA 92697-5100

and NBER

eric.swanson@uci.edu 


\section{Introduction}

Physical currency carries a nominal return of zero, so it is essentially impossible for a central bank to set the short-term nominal interest rate - its conventional monetary policy instrumentsubstantially below zero. ${ }^{1}$ This zero lower bound (ZLB) constraint has required many central banks to pursue unconventional monetary policies to stimulate their economies after the 2007-09 global financial crisis. In this paper, I propose a new method to identify and estimate the effects of these unconventional monetary policies on financial markets and, ultimately, the economy. In particular, I estimate the effects of the U.S. Federal Reserve's "forward guidance" and "largescale asset purchases" (or LSAPs), which were the two main types of unconventional policies pursued by the Fed between January 2009 and October 2015, when its traditional monetary policy instrument, the federal funds rate, was essentially zero.

Understanding the effects of unconventional monetary policy is important for both policymakers and researchers. Many central banks have found themselves increasingly constrained by the zero lower bound in recent years and have turned to a variety of unconventional policies to stimulate their economies, despite the fact that these policies' effects are not well understood. In the present paper, I provide new and improved estimates of these effects and their persistence. The efficacy of unconventional monetary policy is also an important determinant of the cost of the ZLB and the optimal inflation target for an economy. If unconventional monetary policy is relatively ineffective, then the ZLB constraint is more costly, and policymakers should go to greater lengths to avoid hitting it in the first place, such as by choosing a higher inflation target, as advocated by Summers (1991), Blanchard, Dell'Ariccia, and Mauro (2010), Blanchard in The Wall Street Journal (2010), and Ball (2014). On the other hand, if unconventional monetary policy is very effective, then the ZLB constraint is not very costly and there is little reason for policymakers to raise their inflation target on that ground.

The zero lower bound period in the U.S. began on December 16, 2008, when the Federal Reserve's Federal Open Market Committee (FOMC) lowered the federal funds rate-its conventional monetary policy instrument-to essentially zero. The U.S. economy was still in a severe recession, so the FOMC began to pursue unconventional monetary policies to try to stimulate the

\footnotetext{
${ }^{1}$ A few central banks have recently set short-term nominal interest rates slightly below zero by charging banks a fee to hold electronic cash reserves at the central bank. This implies that the "zero lower bound" is not a hard constraint that lies exactly at zero. Nevertheless, nominal interest rates cannot fall too far below zero without leading to widespread conversion of electronic reserves into physical currency. Traditionally, this constraint is still referred to as the "zero lower bound".
} 
Table 1: Major Unconventional Monetary Policy Announcements By the Federal Reserve, 2009-2015

March 18, 2009

November 3, 2010

August 9, 2011

September 21, 2011

January 25, 2012

September 13, 2012

December 12, 2012

December 18, 2013

December 17, 2014

March 18, 2015
FOMC announces it expects to keep the federal funds rate between 0 and 25 basis points (bp) for "an extended period", and that it will purchase $\$ 750 \mathrm{~B}$ of mortgage-backed securities, $\$ 300 \mathrm{~B}$ of longer-term Treasuries, and $\$ 100 \mathrm{~B}$ of agency debt (a.k.a. "QE1")

FOMC announces it will purchase an additional $\$ 600 \mathrm{~B}$ of longer-term Treasuries (a.k.a. "QE2")

FOMC announces it expects to keep the federal funds rate between 0 and 25 bp "at least through mid-2013"

FOMC announces it will sell $\$ 400 \mathrm{~B}$ of short-term Treasuries and use the proceeds to buy $\$ 400 \mathrm{~B}$ of long-term Treasuries (a.k.a. "Operation Twist")

FOMC announces it expects to keep the federal funds rate between 0 and 25 bp "at least through late 2014"

FOMC announces it expects to keep the federal funds rate between 0 and 25 bp "at least through mid-2015", and that it will purchase $\$ 40 \mathrm{~B}$ of mortgagebacked securities per month for the indefinite future

FOMC announces it will purchase $\$ 45 \mathrm{~B}$ of longer-term Treasuries per month for the indefinite future, and that it expects to keep the federal funds rate between 0 and $25 \mathrm{bp}$ at least as long as the unemployment remains above 6.5 percent and inflation expectations remain subdued

FOMC announces it will start to taper its purchases of longer-term Treasuries and mortgage-backed securities to paces of $\$ 40 \mathrm{~B}$ and $\$ 35 \mathrm{~B}$ per month, respectively

FOMC announces that "it can be patient in beginning to normalize the stance of monetary policy"

FOMC announces that "an increase in the target range for the federal funds rate remains unlikely at the April FOMC meeting"

economy further. By far the two most extensively used such policies were "forward guidance"communication by the FOMC about the likely future path of the federal funds rate over the next several quarters - and "large-scale asset purchases", or LSAPs - purchases by the Federal Reserve of hundreds of billions of dollars of longer-term U.S. Treasury bonds and mortgage-backed securities. The goal of both policies was to lower longer-term U.S. interest rates by methods other than changes in the current federal funds rate, and thereby stimulate the economy.

Table 1 reports some of the most notable examples of the FOMC's forward guidance and LSAP announcements during this period. In addition to the examples in the table, incremental news about these policies was released to financial markets at virtually every FOMC meeting, such as updates that a policy was ongoing, was likely to be continued, or might be adjusted. Throughout 2015, for example, the FOMC gave numerous updates about whether a tightening of the federal funds rate was likely to take place at the next one or two FOMC meetings. Finally, the 
U.S. zero lower bound period ended on December 16, 2015, when the FOMC raised the federal funds rate for the first time since the financial crisis, to a range of 0.25 to 0.5 percent.

It's apparent from Table 1 that separately identifying the effects of forward guidance and LSAPs is difficult, because many of the FOMC's announcements provide information about both types of policy simultaneously. Moreover, even in the case of a seemingly clear-cut announcement, such as the LSAP-focused "QE2" announcement on Nov. 3, 2010, both types of policies may still have been at work: in particular, several authors have argued that LSAPs affect the economy either partly or wholly by changing financial markets' expectations about the future path of the federal funds rate (e.g., Woodford, 2012; Krishnamurthy and Vissing-Jorgensen, 2011; Bauer and Rudebusch, 2014). To the extent that this "signaling" channel is operative, even a pure LSAP announcement would have important forward guidance implications. This makes disentangling the two types of policies even more difficult than it might at first seem.

A second major challenge in estimating the effects of unconventional monetary policy announcements is that financial markets are forward-looking, and thus should not react to the component of an FOMC announcement that is expected ex ante; only the unanticipated component should have an effect. But determining the size of the unexpected component of each announcement in Table 1 is very difficult, because there are no good data on what financial markets expected the outcome of each FOMC announcement to be. ${ }^{2}$

A third, related challenge is that the FOMC can sometimes surprise markets through its inaction rather than its actions. For example, on September 18, 2013, financial markets widely expected the FOMC to begin tapering its LSAPs, but the FOMC decided not to do so, surprising markets and leading to a large effect on asset prices despite the fact that no action was announced. ${ }^{3}$ This implies that even dates not listed in Table 1 could have produced a significant surprise in financial markets and led to large effects on asset prices and the economy.

In this paper, I address these challenges by extending the high-frequency approach of Gürkaynak, Sack, and Swanson (2005, henceforth GSS). I first look at the high-frequency (30minute) response of asset prices to FOMC announcements to identify the immediate causal effect of those announcements on financial markets. I then test for the number of dimensions underlying

\footnotetext{
${ }^{2}$ This is in sharp contrast to the case of conventional monetary policy - changes in the federal funds rate- for which we have very good data on financial market expectations ex ante through federal funds futures and other short-term financial market instruments, as discussed by Kuttner (2001), Gürkaynak, Sack, and Swanson (2005, 2007), and others.

3 The Wall Street Journal (2013b,c) reported that "No Taper Shocks Wall Street," and "Bernanke had a free pass to begin that tapering process and chose not to follow [through]... The Fed had the market precisely where it needed to be. The delay today has the effect of raising the benchmark to tapering. .."
} 
those announcement effects and show that they are well described by three dimensions over the period from 1991 to 2015. These dimensions represent the three aspects of FOMC announcements that had the greatest systematic effect on asset prices over the sample; intuitively, these three dimensions are likely to correspond to changes in the federal funds rate, changes in forward guidance, and changes in LSAPs.

I collect the 30-minute asset price responses to each FOMC announcement between 1991 and 2015 and compute the first three principal components of those asset price responses. This estimates the three factors that had the greatest explanatory power for these financial market responses. I search over all possible rotations of these three principal components to find one in which the first factor corresponds to the change in the federal funds rate, the second factor to the change in forward guidance, and the third factor to the change in LSAPs. I build on the earlier work of GSS to separately identify changes in the federal funds rate from forward guidance, and add a new identifying assumption that the LSAP factor is as close to zero as possible during the pre-ZLB period, which separately identifies the LSAP factor. I show that this identification is robust and produces estimates that agree closely with observable characteristics of major FOMC announcements. In this way, I separately identify the size of the federal funds rate, forward guidance, and LSAP component of every FOMC announcement from July 1991 to October 2015.

Once the different components of each FOMC announcement are identified, it's straightforward to estimate the response of different asset prices to each of those components using highfrequency (30-minute or 1-day) regressions. I find that both forward guidance and LSAPs had highly statistically significant effects on a wide variety of assets, including Treasuries, corporate bonds, stocks, exchange rates, and interest rate uncertainty as measured by options. The sizes of these effects are typically comparable to those of conventional monetary policy — changes in the federal funds rate - during the pre-ZLB period. Forward guidance was relatively more effective at moving short-term Treasury yields, while LSAPs were more effective at moving longer-term Treasury yields, corporate bond yields, and interest rate uncertainty (with an increase in LSAPs reducing interest rate uncertainty).

Finally, I investigate whether these effects were persistent-i.e., did they die out quickly as some models of slow-moving capital (e.g., Duffie, 2010; Fleckenstein, Longstaff, and Lustig, 2014) and some empirical work (Wright 2012) suggest, or were the high-frequency impact effects more permanent? I find no significant evidence that either forward guidance or LSAPs had effects that died out over time. The effects of LSAPs seem to be completely persistent, with no tendency 
to die out over the next several months, with the exception of the very influential March 2009 "QE1" announcement, after which bond yields fell sharply but then rebounded strongly over the subsequent weeks as financial markets turned around. The effects of forward guidance seem to be less persistent, with a half-life point estimate of about 1-4 months, but those estimates are not statistically significant and are likely due to the FOMC's forward guidance announcements describing the path of the federal funds rate for only the next several quarters.

The remainder of the paper proceeds as follows. In Section 2, I describe the data and extend the analysis in GSS to allow for additional dimensions of monetary policy. I show that three factors fit the 1991-2015 financial market responses to FOMC announcements very well. I use the identifying assumptions in GSS to separately identify forward guidance from changes in the federal funds rate, and propose a new identifying restriction to separately identify LSAPs from the other two factors. In Section 3, I discuss the results of this identification strategy and show that it is robust. I also show that my estimated forward guidance and LSAP factors correspond closely to identifiable features of major FOMC announcements during the ZLB period. In Section 4, I estimate the effects of forward guidance and LSAPs on Treasury yields, stock prices, exchange rates, and corporate bond yields using high-frequency regressions. In Section 5, I estimate and discuss the persistence of these FOMC announcement effects over the next several months. In Section 6, I use options data to estimate the effects of forward guidance and LSAPs on financial market uncertainty. Finally, in Section 7, I discuss the broader implications of my findings for U.S. monetary policy going forward and for estimating the effects of unconventional monetary policy in other economies. Two technical Appendices contain mathematical details of the identifying assumptions used in Section 2 and the bootstrap procedure used to calculate standard errors in Sections 3-6.

\subsection{Related Literature}

There are now a number of studies that investigate the effects of forward guidance and/or LSAPs on financial markets, especially during the U.S. zero lower bound period. Gürkaynak, Sack, and Swanson (2005) is an early example that measured the effects of the Federal Reserve's pre-2005 forward guidance announcements. In contrast to GSS, I also estimate the effects of the Fed's LSAP announcements, study the peristence of the announcement effects, and investigate the effects on corporate bond yields, exchange rates, and financial market uncertainty as well as stocks, Treasury bonds, and interest rate futures. 
More recently, Gagnon et al. (2011), Krishnamurthy and Vissing-Jorgensen (2011, 2013), and others use high-frequency event studies around a few of the Fed's most notable LSAP announcements to show that those announcements had economically and statistically significant effects on a variety of asset prices. In contrast to these papers, I look at every FOMC announcement from 2009-2015 (and 1991-2008), including announcements that focused on forward guidance rather than, or in addition to, asset purchases. I also separately identify the effects of LSAPs and forward guidance, to contrast the effects of the two types of policies and investigate which one was more effective overall.

Wright (2012) uses identification by heteroskedasticity in a daily VAR from November 2008 to September 2011 to show that Fed announcements had economically and statistically significant effects on longer-term Treasury and corporate bond yields. In contrast to Wright (2012), I distinguish between forward guidance and LSAP announcements and separately estimate the effects of each type of announcement. Wright also estimates that the effects of these unconventional monetary policy announcements tended to die out over time, with a half-life of about 2-3 months. In contrast to Wright, I find that only forward guidance and the very large "QE1" LSAP announcement had effects that died out over time. LSAP announcements more generally seemed to have very persistent effects.

Many studies in the literature also devote considerable attention to identifying and estimating the different mechanisms by which LSAPs affect financial markets. For example, Krishnamurthy and Vissing-Jorgensen (2011) decompose the effects of LSAPs into signaling, duration risk, liquidity, safety, prepayment risk, default risk, and inflation channels, while D'Amico et al. (2012) differentiate between signaling, local scarcity, and duration risk channels. Campbell et al. (2012) and Nakamura and Steinsson (2018) investigate a "Fed information effect" of forward guidance, through which FOMC announcements convey information to financial markets about the Fed's internal forecast for real variables (such as unemployment and GDP), which in turn causes asset prices to move. In the present paper, I do not try to separately estimate the effects of these different channels. Instead, I estimate a "total forward guidance" effect and compare it to a "total LSAP" effect. This is because my focus here is to compare and contrast the overall effectiveness of these two types of policies, rather than the effects of idiosyncratic variations in each type of policy (such as which Treasury or mortgage-backed securities were purchased). While the effects of these variations are interesting and important in their own right, I leave them to these other papers and to future research. I do show in my results, however, that my identifying 
assumptions produce a well-defined and robust average total forward guidance vs. LSAP effect.

\section{Data and Identifying Assumptions}

To separately identify the forward guidance and asset purchase component of each FOMC announcement, I extend the approach of Gürkaynak, Sack, and Swanson (2005). First, I extend the GSS dataset through October 2015 using data obtained from staff at the Federal Reserve Board. The extended data includes the date of every FOMC announcement from July 1991 through October 2015 together with the change in a number of asset prices in a 30-minute window bracketing each announcement. ${ }^{4}$ The asset prices include federal funds futures (the current-month contract rate and the contract rates for each of the next six months), eurodollar futures (the current quarter contract rate and the contract rates for each of the next eight quarters), Treasury bond yields (the 3-month, 6-month and 2-, 5-, 10-, and 30-year maturities), the stock market (S\&P 500), and exchange rates (yen/dollar and dollar/euro).

I collect these asset price responses into a $T \times n$ matrix $X$, with rows corresponding to FOMC announcements and columns corresponding to $n$ different assets; each element $x_{i j}$ of $X$ then reports the 30-minute response of the $j$ th asset to the $i$ th FOMC announcement. As in GSS, we can think of these data in terms of a factor model,

$$
X=F \Lambda+\varepsilon,
$$

where $F$ is a $T \times k$ matrix containing $k \leq n$ unobserved factors, $\Lambda$ is a $k \times n$ matrix of loadings of asset price responses on the $k$ factors, and $\varepsilon$ is a $T \times n$ matrix of white noise residuals. If $k=0$, the data $X$ would be well described by white noise; if $k=1, X$ would be well described as responding linearly to a single factor (such as the change in the federal funds rate) plus white noise; if $k=2$, the data $X$ would be responding to two underlying dimensions of FOMC announcements plus white noise; and so on. Natural candidates for the columns of $F$ would be: i) the surprise component of the change in the federal funds rate around each FOMC meeting, ii) the surprise component of the change in forward guidance, iii) the surprise component of any

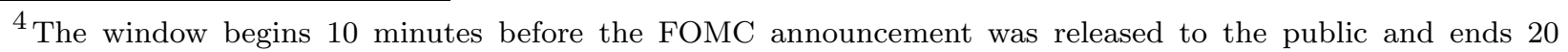
minutes after the FOMC announcement was released. The dataset also includes the dates and times of FOMC announcements and some intraday asset price responses going back to January 1990, but the data for Treasury yield responses begins in July 1991, and those data are an important part of my analysis. Also, as is standard in the literature, I exclude the FOMC announcement on September 17, 2001, which took place after financial markets had been closed for several days following the September 11 terrorist attacks.
} 
LSAP announcements, and iv) any additional dimensions of news about monetary policy or the economy that are systematically revealed in FOMC announcements.

We are interested in estimating and identifying the columns of $F$. For the estimation, I take $X$ to include the first and third federal funds futures contracts, the second, third, and fourth Eurodollar futures contracts, and the 2-, 5-, and 10-year Treasury yields, to focus on the assets that are the most closely related to monetary policy. The first and third federal funds futures contracts provide good estimates of the market expectation of the federal funds rate after the current and next FOMC meetings. ${ }^{5}$ The second through fourth Eurodollar futures contracts provide information about the market expectation of the path of the federal funds rate over a horizon from about 4 months to 1 year ahead. ${ }^{6}$ The 2-, 5-, and 10-year Treasury yields provide information about interest rate expectations and risk premia over longer horizons, out to 10 years. The reason for focusing on some rather than all possible futures contracts is to avoid overlapping contracts, since those are highly correlated for technical rather than policy-related reasons. ${ }^{7}$ In the factor model (1), futures contracts that are highly correlated will tend to show up as a common factor - a column of $F$ - which is not interesting if the correlation is generated by overlapping contracts rather than the way monetary policy is conducted.

Note that, to estimate the factors $F$, I do not need to take a stand on why the interest rates above moved in response to FOMC announcements, only that they did so systematically. For example, medium- or longer-term interest rates might change because of any of the mechanisms described in Krishnamurthy and Vissing-Jorgensen (2011), D’Amico et al. (2012), and Campbell et al. (2012). As long as the interest rate responses to FOMC announcements are systematic, they will be identified as responses to the monetary policy factors $F$ rather than the residuals $\varepsilon_{t}$. Of course, this implies that my estimates of the effects of the factors $F$ represent the total effect of the factor on interest rates through all of the possible channels described by these other authors, as discussed above.

\footnotetext{
${ }^{5}$ As in GSS and Kuttner (2001), these contracts are scaled by the number of days remaining in the month to provide the best estimate of the surprise change in the federal funds rate after the announcement. See GSS and Kuttner (2001) for details.

${ }^{6}$ I follow GSS and switch from federal funds futures to Eurodollar futures at a horizon of about two quarters because Eurodollar futures were much more liquid over this sample than longer-maturity fed funds futures and are thus likely to provide a better measure of financial market expectations at those longer horizons (see Gürkaynak, Sack, and Swanson, 2007).

${ }^{7}$ For example, FOMC announcements are spaced 6 to 8 weeks apart, so the second federal funds futures contract is essentially perfectly correlated with the first (once the latter has been scaled to represent the outcome of the FOMC meeting, as discussed above). Similarly, including the first Eurodollar futures contract provides essentially no additional information beyond the first and third federal funds futures contracts.
} 
Table 2: Tests for the Number of Factors Underlying Interest Rate Responses to FOMC Announcements, 1991-2015

\begin{tabular}{|c|c|c|c|}
\hline $\begin{array}{l}H_{0}: \text { number of } \\
\text { factors equals }\end{array}$ & $\begin{array}{l}\text { degrees of } \\
\text { freedom }\end{array}$ & $\begin{array}{c}\text { Wald } \\
\text { statistic }\end{array}$ & $p$-value \\
\hline 0 & 28 & 88.4 & $3.5 \times 10^{-8}$ \\
\hline 1 & 20 & 52.7 & .00009 \\
\hline 2 & 13 & 26.7 & .014 \\
\hline 3 & 7 & 11.8 & .108 \\
\hline
\end{tabular}

Results from the Cragg-Donald (1997) test for the number of factors $k$ underlying the $213 \times 8$ matrix $X$ of 30-minute asset price responses to FOMC announcements from July 1991 to October 2015. The test is for $H_{0}: k=k_{0}$ vs. $H_{1}: k>k_{0}$. See text for details.

Before estimating F, I first investigate its rank following GSS and Cragg and Donald (1997). Given a null hypothesis of rank $k_{0}$ versus an alternative $k>k_{0}$, the Cragg-Donald test searches over all possible factor models with $k_{0}$ factors to find the one that brings the residuals $\varepsilon$ as close to white noise as possible; the test then measures the distance between the residuals and white noise using a Wald statistic. There are 213 FOMC announcements from July 1991 to October 2015, and eight different assets in $X$, so $X$ has dimensions $213 \times 8$.

The results of the Cragg-Donald rank test are reported in Table 2. The data overwhelmingly reject the hypothesis of rank zero (white noise), so clearly the yield curve responds systematically to FOMC announcements. The hypothesis of rank one is also rejected very strongly, which implies that interest rates respond to FOMC announcements in a multidimensional way-in other words, the surprise change in the federal funds rate (or any other single dimension of monetary policy) is insufficient to explain the responses of interest rates to FOMC announcements. ${ }^{8}$ The hypothesis that $F$ has rank two is also rejected at standard significance levels ( $p$-value of .014), suggesting that even two dimensions of monetary policy are insufficient to explain the response of the yield curve. However, the hypothesis of rank three is not rejected at even the $10 \%$ level, suggesting the data are well-explained by three dimensions of monetary policy underlying the FOMC's announcements. Intuitively, it's natural to think of these three dimensions as corresponding to (the surprise component of) changes in the federal funds rate, forward guidance, and LSAPs, since these were the features of FOMC announcements that received the most attention in financial markets and the financial press.

The results in Table 2 are interesting for several reasons. First, the finding that monetary policy cannot be summarized by any one-dimensional model casts doubt on some authors' use

\footnotetext{
${ }^{8}$ Gürkaynak, Sack, and Swanson (2005) showed that this was also true for their sample, 1991-2004.
} 
of changes in the 1- or 2-year Treasury yield as a sufficient statistic for monetary policy (e.g., Gertler and Karadi, 2015; Hanson and Stein, 2015; Nakamura and Steinsson, 2018). Monetary policy seems to have more than one dimension, at least in terms of its effects on financial markets. Second, as noted by GSS, FOMC announcements are potentially very high-dimensional objects, containing information about the current and future path of interest rates, asset purchases, and the economy. Despite this potential complexity, the effects of monetary policy on the yield curve are surprisingly well summarized by a factor model with just three factors. Third, even though there are many idiosyncratic variations in the way the FOMC described its forward guidance and conducted its LSAPs over the sample, there is enough commonality across announcements that one can still identify an "average forward guidance" factor and an "average LSAP" factor, as I show below. Thus, even though any particular FOMC announcement may have effects that deviate from these averages, those deviations are not systematic enough to require additional factors to fit the data.

Now, the factors $F$ are unobserved and must be estimated. The data suggest that $F$ has rank three, so I begin by extracting the first three principal components of the data $X .{ }^{9}$ These principal components correspond to the three elements of FOMC announcements that had the greatest systematic impact on the assets in $X$ over the sample, and together explain about $94 \%$ of the variation in $X$.

Although principal components explain a maximal fraction of the variation in $X$, they are only a statistical decomposition and do not have a structural interpretation. For example, there is no reason why the first principal component should correspond to the surprise change in the federal funds rate, or forward guidance, or LSAPs - instead, the first principal component is likely to be some combination of two or even all three of these types of announcements. Mathematically, if $F$ and $\Lambda$ characterize the data $X$ in equation (1), and $U$ is any $3 \times 3$ orthogonal matrix, then the matrix $\widetilde{F} \equiv F U$ and loadings $\widetilde{\Lambda} \equiv U^{\prime} \Lambda$ represent an alternative factor model that fits the data $X$ exactly as well as $F$ and $\Lambda$, since it produces exactly the same residuals $\varepsilon$ in equation (1). ${ }^{10}$

Among all these observationally equivalent factor models, we are looking for one in which the three columns of $F$ correspond to (the surprise component of) changes in the federal funds rate, forward guidance, and LSAPs, respectively. This amounts to choosing a rotation matrix $U$

\footnotetext{
${ }^{9}$ The factors $F$ are not required to have any dynamic relationship over time, so Kalman filtering is not a feasible approach to estimating $F$.

${ }^{10}$ The scale of $F$ and $\Lambda$ are also indeterminate: if $\alpha$ is any scalar, then $\alpha F$ and $\Lambda / \alpha$ also fit the data $X$ exactly as well as $F$ and $\Lambda$. I follow the standard practice of normalizing each column of $F$ to have unit variance.
} 
such that the rotated factors $\widetilde{F}$ have this structural interpretation. A $3 \times 3$ orthogonal matrix $U$ is completely determined by three parameters, so identification of $U$ (and hence $\widetilde{F}$ and $\widetilde{\Lambda}$ ) requires three restrictions.

First, I impose that changes in LSAPs have no effect on the current federal funds rate-i.e., $\widetilde{\lambda}_{31}=0$, where $\widetilde{\lambda}_{i j}$ denotes the $(i, j)$ th element of $\widetilde{\Lambda}$. Since the FOMC's major LSAP announcements all occurred during the ZLB period after 2008, this should be relatively uncontroversial.

Second, following GSS, I impose that changes in forward guidance also have no effect on the current federal funds rate-i.e., $\widetilde{\lambda}_{21}=0$. Although there are important examples of forward guidance before the ZLB period, as discussed in GSS, this identifying assumption is justified by defining forward guidance to be the component of FOMC announcements that conveys information about the future path of short-term interest rates above and beyond changes in the target federal funds rate itself. ${ }^{11}$ This is the definition of forward guidance (or the path factor) used by GSS and that I also use in this paper.

Third and finally, I impose the restriction that the LSAP factor is as small as possible in the pre-ZLB period. In other words, I compute the sum of squared values of the third factor, $\widetilde{F}_{3}=F U_{3}$, where $U_{3}$ denotes the third column of $U$, over the subsample from 1991 to 2008 , and choose the elements of $U_{3}$ to minimize this sum of squares subject to the first two constraints above. The idea is that FOMC announcements before the ZLB period did not have significant LSAP implications in general and thus the LSAP factor should be small during this period. ${ }^{12}$ Together, these three restrictions uniquely identify $U$, and hence $\widetilde{F}$ (up to a sign normalization for each column). ${ }^{13}$ Mathematical details of these restrictions are provided in Appendix A.

\footnotetext{
${ }^{11}$ An increase in the federal funds rate is typically not a one-off decision, but is usually followed by additional funds rate hikes down the road. Thus, a surprise change in the federal funds rate today has implications for future values of the federal funds rate as well. What distinguishes the forward guidance factor is that it moves market expectations of future values of the federal funds rate without any change in the current federal funds rate target.

12 Note that the pre-2009 LSAP factor will still have nonzero values, even though they are small. This could be due to the Fed's monetary policy announcements having implications for its open market operations, or simply because there is some sampling variability in the estimation procedure. Also note that we cannot impose the restriction that the federal funds rate factor - the first column of $\widetilde{F}$ - is as small as possible during the ZLB period, because the first two restrictions already identify the federal funds rate factor, so this third restriction would not help to separate forward guidance from LSAPs.

13 One can also regard the orthogonality of $U$ and the columns of $\widetilde{F}$ as additional assumptions that help achieve identification. Intuitively, this orthogonality assumption is just part of the definition of each factor-i.e., changes in the federal funds rate factor typically have implications for future interest rates, but those changes are part of the effects of the federal funds rate itself; the forward guidance factor captures effects on longer-term interest rates that are above and beyond the usual effects of changes in the federal funds rate. Similarly, the LSAP factor captures effects on the yield curve that are above and beyond the usual effects of changes in forward guidance, etc.
} 


\section{Table 3: Estimated Effects of Conventional and Unconventional Monetary Policy Announcements on Interest Rates, 1991-2015}

$\begin{array}{lcccccccc} & \text { MP1 } & \text { MP2 } & \text { ED2 } & \text { ED3 } & \text { ED4 } & \text { 2y Tr. } & \text { 5y Tr. 10y Tr. } \\ \text { (1) change in federal funds rate } & 8.78 & 6.22 & 5.55 & 5.21 & 4.43 & 3.68 & 2.04 & 0.95 \\ \text { (2) change in forward guidance } & 0.00 & 1.21 & 4.16 & 5.32 & 6.02 & 4.85 & 5.09 & 3.92 \\ \text { (3) change in LSAPs } & 0.00 & 0.85 & 1.42 & 1.37 & 1.04 & -0.32 & -3.71 & -5.68\end{array}$

Coefficients in the table correspond to elements of the structural loading matrix $\widetilde{\Lambda}$, in basis points per standard deviation change in the monetary policy instrument. MP1 and MP2 denote scaled changes in the first and third federal funds futures contracts, respectively; ED2, ED3, and ED4 denote changes in the second through fourth Eurodollar futures contracts; and 2y, 5y, and 10y Tr. denote changes in 2-, 5-, and 10-year Treasury yields. See text for details.

\section{The FOMC's Forward Guidance and LSAP Announcements}

Table 3 reports the loading matrix $\widetilde{\Lambda}$ that results from the three identifying assumptions above. Each rotated factor is normalized to have a unit standard deviation, so the coefficients in the table are in units of basis points (bp) per standard deviation change in the monetary policy instrument. ${ }^{14}$

A one-standard-deviation increase in the federal funds rate factor is estimated to raise the current federal funds rate by about $8.8 \mathrm{bp}$, the expected federal funds rate at the next FOMC meeting by about $6.2 \mathrm{bp}$, the second through fourth Eurodollar futures rates by 5.6, 5.2, and 4.4bp, respectively, and the 2-, 5-, and 10-year Treasury yields by about 3.7, 2, and 1bp, respectively. The effects of a surprise change in the federal funds rate are thus largest at the short end of the yield curve and die off monotonically as the maturity of the interest rate increases, consistent with the estimates in Kuttner (2001) and GSS.

The effects of forward guidance, in the second row, are quite different. By construction, a shock to the forward guidance factor has no effect on the current federal funds rate. At longer maturities, however, the forward guidance factor's effects increase, peaking at a horizon of about one year and diminishing at longer horizons. ${ }^{15}$ Again, this is consistent with the estimates in

\footnotetext{
${ }^{14}$ I normalize the scale of the federal funds rate factor to have a unit standard deviation from July 1991 to December 2008, because the federal funds rate essentially does not change after December 2008. This scale convention is more intuitive than a full-sample unit standard deviation would be, and also facilitates comparison to previous results in the literature. Similarly, I normalize the LSAP factor to have a unit standard deviation over the period from January 2009 to October 2015. I normalize the forward guidance factor to have a unit standard deviation over the whole sample.

${ }^{15}$ Note that these estimates represent an average forward guidance effect over the sample. Some FOMC announcements may have had an earlier or later peak effect than the average estimated in row 2 , but these differences were not large enough or systematic enough to require another factor to fit the data.
} 
GSS and Campbell et al. (2012).

The effects of LSAPs, reported in the third row, are quite different from the first two rows. Like forward guidance, a change in the LSAP factor has no effect on the current federal funds rate, by construction. Unlike forward guidance and changes in the federal funds rate, the effect of LSAPs is small at short maturities and much larger at the long end of the yield curve. This is consistent with several authors' findings that LSAPs have a substantial impact on longer-term Treasury yields (e.g., Gagnon et al., 2011; Krishnamurthy and Vissing-Jorgensen, 2011, 2013; Swanson, 2011). A one-standard deviation increase in the LSAP factor causes 5- and 10-year Treasury yields to fall about 3.7 and $5.7 \mathrm{bp}$, respectively, on average. ${ }^{16}$ An increase in LSAPs also causes short-term yields to rise slightly, on average, although this effect is quantitatively small and not statistically signficant, as I show in the next section.

The results in Table 3 are interesting for several reasons. First, as noted above, the coefficients in each row are generally consistent with other estimates in the literature, such as Kuttner (2001), GSS (2005), Gagnon et al. (2011), and Krishnamurthy and Vissing-Jorgensen (2011, 2013). This provides some initial confirmation of the identifying assumptions above.

Second, Table 3 shows that unconventional monetary policy was effective, at least in a 30minute window around FOMC announcements. Moreover, both types of unconventional monetary policy — forward guidance and LSAPs — were about as effective as changes in the federal funds rate, in the sense that the coefficients have similar magnitudes across the three rows (although each policy had a peak effect at a different point along the yield curve). This is an important initial finding of the effectiveness of the two types of unconventional policy.

Third, I estimate that the effects of forward guidance and LSAPs are very different from each other. (Indeed, it is this strong contrast that makes identification of the two factors empirically robust.) These differences imply that the LSAP factor affected financial markets through more than just a "signaling channel" (e.g., Woodford, 2012; Bauer and Rudebusch, 2014). Recall that, according to the pure signaling view, LSAPs affect financial markets only because they increase the central bank's commitment to follow through with its forward guidance (because the bank would lose money on those LSAPs if it raised interest rates sooner than financial markets expect). If that were the case, then the second and third rows of Table 3 should be much more similar in terms of their relative effects on yields. This observation is also supported by Table 2, which

\footnotetext{
${ }^{16}$ As with forward guidance, these estimates represent an average LSAP effect over the sample. Some FOMC announcements may have had a slightly different effect than the average estimated in row 3 , but these differences were not large enough or systematic enough to require another factor to fit the data.
} 
showed that no two factors (such as changes in the federal funds rate and forward guidance) are sufficient to explain financial markets' reactions to FOMC announcements - a third factor is required.

Fourth and finally, the differences across the three rows in Table 3 cast doubt on some authors' use of the 1- or 2-year Treasury yield as a sufficient statistic for monetary policy (e.g., Gertler and Karadi, 2015; Hanson and Stein, 2015; Nakamura and Steinsson, 2018). A 10bp change in the 2-year Treasury yield has very different effects on short- and long-term interest rates (and other financial market assets, as shown below) if it is caused by a change in the current federal funds rate as opposed to a change in forward guidance or LSAPs. For example, a 23.9bp (2.7-standard-deviation) change in the federal funds rate has a 10bp effect on the 2-year Treasury yield and 2.6bp effect on the 10-year yield, while a 2.1-standard deviation change in forward guidance has the same effect on the 2-year Treasury but more than three times the effect on the 10-year yield (8.1bp) and on corporate bond yields, as shown below. A change in LSAPs that causes the 2-year Treasury yield to fall 10bp would cause the 10-year yield to fall 177bp. Estimates by the above authors capture a weighted average of the effects of these three different types of monetary policy, but the effects of a given change in the 2-year Treasury yield in practice will depend on how that change in the 2-year yield is implemented.

\subsection{Robustness of the Identified Factors}

The federal funds rate, forward guidance, and LSAP factors identified above are very robust to reasonable variations in the identifying assumptions. For example, Swanson (2017) considers an alternative set of assumptions that splits the sample into pre-ZLB and ZLB periods, uses the GSS (2005) identifying assumptions in the pre-ZLB period to separately identify changes in the federal funds rate and forward guidance, and then uses the ZLB period to separately identify forward guidance and LSAPs. The estimated factors from that procedure are very similar to those estimated here (correlations of 95 to over $99 \%$ ).

Alternatively, one can simply define the federal funds rate factor to be the surprise change in the federal funds rate itself, the forward guidance factor to be any additional movements in the 2-year Treasury yield that are orthogonal to the change in the federal funds rate, and the LSAP factor to be any additional movements in the 10-year Treasury yield that are orthogonal to the first two factors. ${ }^{17}$ This very simple set of identifying assumptions produces factors that have a

\footnotetext{
${ }^{17}$ In particular, for this alternate identification, I take the 30-minute change in the first federal funds futures
} 
correlation of $96 \%, 96 \%$, and $89 \%$, respectively, with the three factors estimated above using my main identifying assumptions.

Intuitively, the three factors are well identified in the data because their effects on the yield curve are so different from each other, as can be seen in Table 3. Movements in these three different points along the yield curve are very easy to separate in the data, so variations in the identifying assumptions have relatively small effects on the estimated factors.

\subsection{Correspondence of Factors to Notable FOMC Announcements}

Figure 1 reports how well these estimated factors correspond to observable characteristics of major FOMC announcements during the ZLB period, January 2009 to October 2015. (For a similar analysis of the federal funds rate and forward guidance factors in the pre-ZLB period, see GSS.) The dashed blue line in the figure depicts the full-sample estimate of the forward guidance factor, and the solid orange line the full-sample LSAP factor multiplied by -1 . This sign renormalization for the LSAP factor makes its behavior in the figure more intuitive-i.e., positive values in the figure correspond to monetary policy tightenings and negative values to monetary policy easings. Figure 1 also contains brief annotations for some of the larger observations.

The most striking observation in Figure 1 by far is the negative 5.6-standard-deviation LSAP announcement on March 18, 2009, near the beginning of the ZLB sample. This observation corresponds to the announcement of the FOMC's first LSAP program, often referred to as "QE1" in the press. ${ }^{18}$ The key elements of this program are listed in Table 1, and the announcement seems to have been a major surprise to financial markets, given the huge estimated size of the factor on that date. According to my identification, this announcement is dominated by its LSAP implications, although I also estimate a negative 1.5-standard-deviation forward guidance easing as well. Given that this FOMC announcement placed such a large emphasis on asset purchases,

contract, scaled as above, and define that to be the federal funds rate factor; I take the 30-minute change in the 2-year Treasury yield, regress that on a constant and the federal funds rate factor, and define the residuals to be the forward guidance factor; and I take the 30-minute change in the 10-year Treasury yield, regress that on a constant and the first two factors, and define the residuals to be the LSAP factor. This is essentially the same approach taken in very recent papers by Rogers, Scotti, and Wright (2018) and Gilchrist, Yue, and Zakrajsek (2018), although the latter authors do not distinguish between changes in the federal funds rate and forward guidance.

18 The "QE1" program began on November 25, 2008, when the Federal Reserve Board (rather than the FOMC) announced it would purchase $\$ 600$ billion of mortgage-backed securities and $\$ 100$ billion of debt issued by the mortgage-related government-sponsored enterprises. The term "QE1" typically refers to both this earlier program and the huge expansion of that program announced on March 18, 2009. My analysis in this paper excludes the $11 / 25 / 08$ announcement because it is not an FOMC announcement, but my results are not sensitive to its inclusion. 


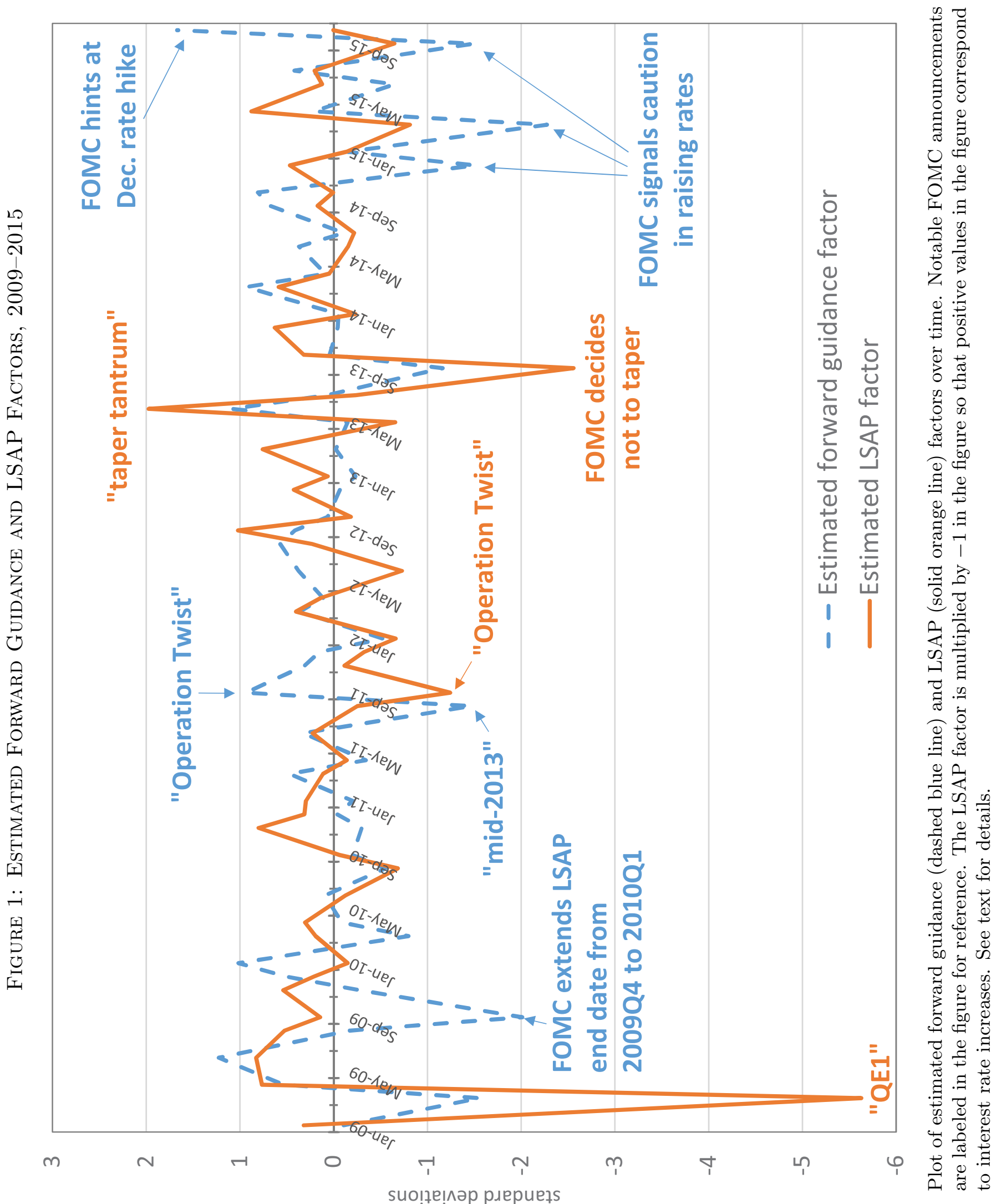


these results seem very reasonable. ${ }^{19}$

Three occasions near the end of the sample-December 17, 2014, March 18, 2015, and September 17, 2015 - are also very striking. On these dates, markets expected the FOMC to signal that a hike in the federal funds rate would be coming in the near future. In each of these cases, the FOMC surprised markets by signaling additional caution in raising the funds rate. ${ }^{20}$ My identification attributes each of these announcements to changes in FOMC forward guidance, which is very much in line with the market commentary.

The last observation in Figure 1, October 28, 2015, is also very supportive. On that date, the FOMC kept the federal funds rate at zero, but stated that a rate hike in December was being considered - an unusually explicit signal that significantly altered markets' expectations of a rate hike at the upcoming meeting (The Wall Street Journal, 2015f,g). The Fed's statement caused short- and medium-term interest-rate futures and Treasury yields to jump, and is thus identified by my estimation as a significant increase in forward guidance, with no change in LSAPs.

The middle of 2013 corresponds to the so-called "taper tantrum" in financial markets. On June 19, I estimate a substantial, two-standard-deviation decrease in the LSAP factor (which is positive in Figure 1 becuase it represents a monetary policy tightening). There is little change in the FOMC statement on that date, but as reported by The Wall Street Journal, the FOMC released economic projections along with the statement that showed a substantial increase in the FOMC's economic outlook. Given earlier remarks by then-Chairman Bernanke that the FOMC could begin tapering its asset purchases soon, markets interpreted this as a signal that a tapering was imminent. ${ }^{21}$ The flip side of this announcement occurred on September 18, 2013, when the

\footnotetext{
${ }^{19}$ It's interesting to note that the FOMC's subsequent "QE2" program, described in Table 1, does not show up as a major event in Figure 1, probably becuase it was anticipated by financial markets in advance (see, e.g., Forbes 2010). Looking at Figure 1 around the November 3, 2010, announcement date of the program, there is essentially no estimated effect, because the interest rates included in the estimation responded very little to the announcement. Thus, even though the QE2 announcement was roughly one-half as large as the earlier QE1 announcement in terms of the quantity of purchases, the surprise component of that announcement appears to have been dramatically smaller.

${ }^{20}$ On Dec. 17, 2014, markets expected the FOMC to remove its statement that it would keep the federal funds rate at essentially zero "for a considerable time". Not only did the FOMC leave that phrase intact, it announced that "the Committee judges it can be patient in beginning to normalize the stance of monetary policy," which was substantially more dovish than markets had expected (e.g., "U.S. stocks surged... after the Federal Reserve issued an especially dovish policy statement," The Wall Street Journal, 2014). On Mar. 18, 2015, the FOMC revised its projections for U.S. output, inflation, and the federal funds rate substantially below what markets had expected. The revised forecast was read by financial markets "as a sign that the central bank would take its time in raising [rates]" (The Wall Street Journal, 2015a,b). And on Sep. 17, 2015, the FOMC declined to raise the federal funds rate, issued a statement that was widely regarded as more dovish than expected, and released interest rate forecasts that were substantially lower than before (The Wall Street Journal, 2015c,d,e).

${ }^{21}$ For example, The Wall Street Journal (2013a) reported that "Bond prices slumped, sending the yield on the 10-year Treasury note to its highest level in 15 months, as the Federal Reserve upgraded its growth projections for the U.S. economy... Stronger U.S. growth is widely perceived in the market as heralding an earlier end to the
} 
FOMC was widely expected to begin tapering its asset purchases but opted not to do so. The Wall Street Journal (2103b,c) reported that "No Taper Shocks Wall Street," and "The move, coming after Fed officials spent months alerting the public that they might begin to pare their $\$ 85$ billion-a-month bond-buying program at the September policy meeting, marks the latest in a string of striking turnabouts from Washington policy makers that have whipsawed markets in recent days." 22 I estimate this announcement to be a very large, 2.6-standard-deviation LSAP easing. Thus, both of these "taper tantrum" announcements seem to be correctly identified as movements in the LSAP factor.

There are a number of other notable observations in Figure 1 as well. August 9, 2011, marked the first time the FOMC gave explicit (rather than implicit) forward guidance about the likely path of the federal funds rate over the next several quarters. In that announcement, described in Table 1, the FOMC stated that it expected the current (essentially zero) level of the federal funds rate would be appropriate "at least through mid-2013", a date almost two years in the future. My estimates imply the announcement on this date was a negative 1.5-standarddeviation surprise in forward guidance, with essentially no LSAP component.

September 21, 2011, corresponds to "Operation Twist", a program where the FOMC sold about $\$ 400$ billion of short-term Treasury securities in its portfolio and used the proceeds to purchase a like quantity of long-term Treasuries. As can be seen in Figure 1, I estimate this announcement had a negative 1.2-standard-deviation LSAP effect (which is intuitive), and a positive 1-standard-deviation forward guidance effect, which is perhaps surprising. This latter effect is due to the fact that shorter-maturity interest rates rose in response to the FOMC announcementpresumably due to a change in risk premia on those securities resulting from the large increase in expected sales by the Fed. Although this is probably not an example of forward guidance by the FOMC per se, it nevertheless looks like forward guidance in the data because of the unusual implication of the announcement for short-term Treasury yields. Thus, even though my identification arguably misses some subtleties on this particular date, the estimates coming out of the identification are sensible.

Finally, I estimate a negative two-standard-deviation forward guidance announcement on September 23, 2009. On this date, the FOMC stated it would extend its asset purchase program

Fed's program of purchasing $\$ 85$ billion in bonds each month..."

22 The Wall Street Journal (2013b,c) also reported that "Bernanke had a free pass to begin that tapering process and chose not to follow [through]... The Fed had the market precisely where it needed to be. The delay today has the effect of raising the benchmark to tapering..." 
by an additional three months, through 2010Q1. From the text of the FOMC statement alone, it's unclear whether the announcement should be regarded as forward guidance or LSAPs, or both. My estimates characterize this announcement as forward guidance, based on the way financial markets responded (i.e., shorter-term interest rates moved more than longer-term interest rates). It's important to bear in mind that the U.S. economy was beginning to recover by late 2009 and financial markets expected the FOMC to begin raising the federal funds rate in just a few quarters (Swanson and Williams, 2014), but not until a few meetings after completing its asset purchase program. Thus, an extension of the end date of the LSAP program was taken by markets to imply a correspondingly later liftoff date for the federal funds rate.

\subsection{Scale of Forward Guidance and LSAP Factors}

The forward guidance and LSAP factors estimated above and plotted in Figure 1 are normalized to have a unit standard deviation. Similarly, the loadings in Table 3 are for these normalized factors and thus represent a basis points per standard deviation effect. For policymakers, however, it's useful to express these effects in terms of units that are more directly observable.

A natural measure of forward guidance is a 25bp change in the Eurodollar futures rate one year ahead, ED4. Note that a forward guidance announcement of this size would be very large by historical standards, about 4.15 standard deviations. Multiplying the coefficients in the second row of Table 3 by 4.15 implies that the effects on the 5 - and 10-year Treasury yields would be about 21.1 and $16.3 \mathrm{bp}$, respectively. The interpretation is that, if the FOMC gave forward guidance for the federal funds rate that was about 25bp lower one year ahead, then the 5- and 10-year Treasury yields would decline by about 21 and 16bp, on average.

For LSAPs, we would like the units to be in billions of dollars of purchases, which is a more difficult transformation. Nevertheless, a number of estimates in the literature suggest that a $\$ 600$ billion LSAP operation in the U.S., distributed across medium- and longer-term Treasury securities, leads to a roughly 15bp decline in the 10-year Treasury yield (see, e.g., the survey of estimates in Swanson, 2011, and Table 1 of Williams, 2013). Using this estimate as a benchmark implies that the coefficients in the third row of Table 3 correspond to a roughly $\$ 225$ billion surprise LSAP announcement. In other words, if the FOMC announced a new LSAP program that was about $\$ 225$ billion larger than markets expected, the effects should be about the same as those provided in the third row of Table 3, on average. 
Table 4: Estimated Effects of Changes in the Federal Funds Rate, Forward Guidance, and LSAPs on U.S. Treasury Yields

$$
\text { 6-month 2-year 5-year 10-year 30-year }
$$

(A) estimated effects of federal funds rate and forward guidance, Jul. 1991-Dec. 2008

$\begin{array}{lccccc}\text { change in federal funds rate } & 4.11^{* * *} & 3.70^{* * *} & 2.02^{* * *} & 0.82^{* * *} & -0.15 \\ \quad(\text { std. err.) } & (.223) & (.267) & (.264) & (.239) & (.220) \\ \quad \text { t } \text {-stat.] } & {[18.42]} & {[13.85]} & {[7.66]} & {[3.44]} & {[-0.70]} \\ \text { change in forward guidance } & 2.87^{* * *} & 4.81^{* * *} & 4.59^{* * *} & 3.44^{* * *} & 2.22^{* * *} \\ \quad \text { (std. err.) } & (.503) & (.837) & (.821) & (.643) & (.460) \\ \quad \text { t } \text {-stat. } & {[5.71]} & {[5.75]} & {[5.58]} & {[5.34]} & {[4.82]} \\ \text { Regression } R^{2} & .80 & .95 & .87 & .80 & .53 \\ \text { \# Observations } & 158 & 158 & 158 & 158 & 158\end{array}$

(B) estimated effects of forward guidance and LSAPs, Jan. 2009-Oct. 2015

$\begin{array}{lccccc}\text { change in forward guidance } & 1.19^{* * *} & 5.14^{* * *} & 6.22^{* * *} & 3.06^{* * *} & 0.14 \\ \quad(\text { std. err.) } & (.272) & (.811) & (1.010) & (.627) & (.308) \\ \quad \text { t } \text {-stat.] } & {[4.37]} & {[6.33]} & {[6.15]} & {[4.88]} & {[0.45]} \\ \text { change in LSAPs } & 0.19 & 0.20 & -2.92^{* * *} & -6.49^{* * *} & -5.77^{* * *} \\ \quad \text { (std. err.) } & (.179) & (.332) & (.425) & (.883) & (.840) \\ \quad \text { t } \text {-stat.] } & {[1.08]} & {[0.59]} & {[-6.86]} & {[-7.35]} & {[-6.87]} \\ \text { Regression } R^{2} & .40 & .93 & .95 & .98 & .81 \\ \text { \# Observations } & 55 & 55 & 55 & 55 & 55\end{array}$

Coefficients $\beta$ from regressions $\Delta y_{t}=\alpha+\widetilde{F}_{t} \beta+\varepsilon_{t}$, where $t$ indexes FOMC announcements, $y$ denotes a given Treasury yield, $\widetilde{F}$ denotes the monetary policy factors estimated previously, and $\Delta$ is the intraday change in a 30-minute window bracketing each FOMC announcement. Coefficients are in units of basis points per standard deviation change in the monetary policy instrument. Bootstrapped standard errors in parentheses and $t$-statistics in square brackets; ${ }^{* * *}$ and ${ }^{* *}$ denote statistical significance at the $1 \%$ and $5 \%$ levels, respectively. See text for details.

\section{The Effects of Forward Guidance and LSAPs on Asset Prices}

Once we've estimated the forward guidance and LSAP components of each FOMC announcement, above, it's straightforward to estimate the effects of those policies on a variety of asset prices using high-frequency regressions, as follows.

\subsection{Treasury Yields}

Table 4 reports the responses of 6-month and 2-, 5-, 10-, and 30-year Treasury yields to changes in the federal funds rate and forward guidance from July 1991 to December 2008, and changes in 
forward guidance and LSAPs from January 2009 to Occtober 2015. ${ }^{23}$ Although full-sample point estimates for the 2-, 5-, and 10-year Treasury yields were already reported in Table 3, Table 4 reports standard errors, $t$-statistics, results for the pre-ZLB and ZLB subsamples, and results for the 6-month and 30-year Treasury yields. Each column of the table reports estimates from an OLS regression of the form

$$
\Delta y_{t}=\alpha+\beta \widetilde{F}_{t}+\varepsilon_{t},
$$

where $t$ indexes FOMC announcements, $y$ denotes a particular Treasury yield, $\Delta$ the change in a 30-minute window bracketing each FOMC announcement, $\widetilde{F}$ the monetary policy factors estimated above, and $\varepsilon$ a regression residual. As in Table 3, the coefficients in Table 4 are in units of basis points per standard deviation surprise in the monetary policy tool.

The coefficients in the top panel of Table 4 are very similar to those estimated previously by GSS (2005) and Campbell et al. (2012) for the pre-ZLB period, and are included here for completeness and comparability to the earlier literature. Standard errors and $t$-statistics are computed using 10,000 bootstrap samples to account for the fact that the monetary policy factors $\widetilde{F}$ are generated regressors (see Appendix B for details). Nevertheless, the responses of Treasury yields to the federal funds rate and forward guidance factors are typically highly statistically significant, with $t$-statistics exceeding 5 or even 10 . There is essentially no doubt that Treasury yields respond systematically to FOMC announcements. As discussed in the previous section and in GSS, the effects of changes in the federal funds rate decline steadily with maturity, while forward guidance has a hump-shaped effect on the yield curve.

The bottom panel of Table 4 reports results for changes in forward guidance and LSAPs during the ZLB period, 2009-15. These results are also typically highly statistically significant, with $t$-statistics often exceeding 4 . The regression $R^{2}$ values are very high in many cases as well (over 93 percent), so these two factors explain a large share of the variation in Treasury yields around FOMC announcements. The effects of forward guidance are hump-shaped and generally very similar to the pre-ZLB period, although the effect on the 6-month Treasury yield is noticeably smaller, due to that yield being so close to zero and thus much less sensitive to news for much of the ZLB sample (Swanson and Williams, 2014). ${ }^{24}$ The effects of forward guidance also fall to

\footnotetext{
${ }^{23}$ Results for the 3-month Treasury yield are not reported, since the 3-month Treasury yield generally did not respond to news during the ZLB period — see Swanson and Williams (2014) — and is thus less interesting.

${ }^{24}$ The peak effect of forward guidance is also a little bit larger and later than in the pre-ZLB period, on average, which would be consistent with the FOMC's greater emphasis on longer-dated forward guidance during the ZLB period.
} 
essentially zero for the 30-year yield during this period.

As noted previously, LSAPs had their greatest effect on long-term interest rates, particularly the 10-year Treasury yield, likely because the FOMC focused its bond purchases around that maturity. The effect on the 30-year yield is also quite large and highly statistically significant. In contrast, LSAPs had a slight positive effect on the short end of the yield curve, about $0.2 \mathrm{bp}$ per standard deviation, although those effects are not statistically significant. One explanation for this result is that the Federal Reserve may have sold off or reduced its demand for short-term Treasuries in order to buy longer maturities, as in the "Operation Twist" period from late 2011 through 2012.

Taken together, these results imply that both forward guidance and LSAPs were effective during the ZLB period, at least in a 30-minute window around FOMC announcements. As noted previously in Table 3, their effects are broadly similar in magnitude to those of changes in the federal funds rate during the pre-ZLB period, although the peak effects occur at different points along the yield curve.

\subsection{Stock Prices and Exchange Rates}

Table 5 reports analogous results for the S\&P 500 stock index and dollar-euro and dollar-yen exchange rates. The form of the regressions is the same as in equation (2), except the dependent variable in each regression is now 100 times the log change in the asset price in each column.

As before, results for changes in the federal funds rate and forward guidance in the preZLB period are included for completeness. A one-standard-deviation increase in the federal funds rate causes stock prices to fall about 0.3 percent and the dollar to appreciate about 0.1 percent, with bootstrapped $t$-statistics of 2.5 or greater. A one-standard-deviation tightening of forward guidance causes stocks to fall a bit less, about 0.15 percent, but the dollar appreciates a bit more, about 0.15 percent, and these effects are also highly statistically significant.

During the ZLB period (bottom panel), the effects of forward guidance were somewhat larger, leading to a drop in stock prices of about 0.25 percent and an appreciation of the dollar of about $0.25-0.35$ percent, and these effects are highly statistically significant. For LSAPs, a one-standard-deviation increase (which causes interest rates to fall) causes stock prices to rise about 0.1 percent and the dollar to depreciate $0.2-0.3$ percent. The effect of LSAPs on stocks is not statistically significant, but those on the dollar are highly significant. Interestingly, the

regression $R^{2}$ for the dollar are much higher during the ZLB period than before, while the $R^{2}$ for 
Table 5: Estimated Effects of Changes in the Federal Funds Rate, Forward Guidance, and LSAPs on Stock Prices and Exchange Rates

$$
\text { S\&P500 \$/euro \$/yen }
$$

(A) estimated effects of federal funds rate and forward guidance, Jul. 1991-Dec. 2008

$\begin{array}{lccc}\text { change in federal funds rate } & -0.32^{* * *} & -0.11^{* *} & -0.13^{* * *} \\ \quad(\text { std. err. }) & (.044) & (.044) & (.044) \\ \quad \text { t } \text {-stat. }] & {[-7.26]} & {[-2.55]} & {[-2.91]} \\ \text { change in forward guidance } & -0.16^{* * *} & -0.16^{* * *} & -0.14^{* * *} \\ \quad \text { std. err. } & (.049) & (.049) & (.047) \\ \quad \text { t } \text {-stat. } & {[-3.31]} & {[-3.15]} & {[-2.91]} \\ \text { Regression } R^{2} & .31 & .15 & .14 \\ \text { \# Observations } & 158 & 158 & 158\end{array}$

(B) estimated effects of forward guidance and LSAPs, Jan. 2009-Oct. 2015

$\begin{array}{lccc}\text { change in forward guidance } & -0.26^{* * *} & -0.37^{* * *} & -0.24^{* *} \\ \quad(\text { std. err.) } & (.093) & (.102) & (.097) \\ \quad \text { t-stat.] } & {[-2.79]} & {[-3.63]} & {[-2.50]} \\ \text { change in LSAPs } & 0.12 & 0.21^{* * *} & 0.29^{* * *} \\ \quad \text { (std. err.) } & (.074) & (.078) & (.076) \\ \quad \text { t } \text {-stat.] } & {[1.59]} & {[2.72]} & {[3.82]} \\ \text { Regression } R^{2} & .28 & .68 & .79 \\ \text { \# Observations } & 55 & 55 & 55\end{array}$

Coefficients $\beta$ from regressions $\Delta \log x_{t}=\alpha+\widetilde{F}_{t} \beta+\varepsilon_{t}$, where $t$ indexes FOMC announcements, $x$ is the asset price, $\widetilde{F}$ denotes the monetary policy factors estimated previously, and $\Delta$ is the intraday change in a 30-minute window bracketing each FOMC announcement. Coefficients are in units of percentage points per standard deviation change in the monetary policy instrument. Bootstrapped standard errors in parentheses and $t$-statistics in square brackets; ${ }^{* * *}$ and ${ }^{* *}$ denote statistical significance at the $1 \%$ and $5 \%$ levels, respectively. See text for details.

stocks is low in both periods, due to the high and idiosyncratic volatility of stocks after FOMC announcements.

These results are all intuitive. For the dollar, the effects have the signs one would expect from uncovered interest parity, given the response of interest rates in Table 4. That is, an increase in U.S. interest rates makes U.S. dollar investments more attractive relative to foreign investments, and tends to drive the value of the dollar up. For stocks, the effects are consistent with increases in interest rates reducing the present value of stocks' future dividends through both a discounting channel and a weaker economy.

Most importantly, these results show that forward guidance and LSAPs were effective at 
moving stock prices and exchange rates as well as Treasury yields. In addition, both of these unconventional policies had effects that were roughly comparable to those of changes in the federal funds rate in the pre-ZLB period. The unconventional policies' effects on the dollar were a bit greater than for conventional monetary policy, and the effects on stock prices a bit less, but these differences are generally not statistically significant. Compared to each other, forward guidance and LSAPs seem to be about equally effective at moving stock prices and exchange rates, although the effect of LSAPs on stocks is not very precisely estimated.

\subsection{Corporate Bond Yields and Spreads}

Table 6 reports analogous results for corporate bond yields and spreads. Corporate bonds are less frequently traded than Treasuries, stocks, and foreign exchange, so the regressions in Table 6 use the one-day change in corporate bond yields and spreads around each FOMC announcement as the dependent variable, rather than the 30-minute change. To measure corporate yields, I use the Aaa and Baa indexes of long-term seasoned corporate bond yields from Moody's.

The top panel reports the effects of changes in the federal funds rate and forward guidance in the pre-ZLB period. The federal funds rate has no significant effect on either corporate bond yields or spreads. In contrast, the effects of forward guidance on corporate yields are larger and highly statistically significant, with $t$-statistics of more than 4 . Forward guidance has a slight negative effect on spreads, however, as the 10-year Treasury yield responds to the announcement by more than corporate yields.

The bottom panel reports the effects of forward guidance and LSAPs during the ZLB period. Surprisingly, forward guidance had essentially no effect on corporate yields during this period, although the effect on spreads was negative because 10-year Treasury yields rose modestly in response to increases in forward guidance. The effect is statistically significant for the BaaTreasury spread, with a $t$-statistic of about 2.4 .

The effect of LSAPs on corporate bond yields is much larger and more significant. An increase in LSAPs causes Aaa and Baa yields to fall about 5bp per standard deviation, with $t$-statistics of more than 4. The effect of LSAPs on the 10-year Treasury yield is even larger, however, so corporate bond spreads rise in response to LSAPs. ${ }^{25}$ This result echoes Krishnamurthy

\footnotetext{
25 The 10-year yield response in Table 3 is estimated to be about $-6.5 \mathrm{bp}$, while the effect implied in Table 6 is a bit larger, about $-8.1 \mathrm{bp}$. There are two reasons for this difference: first, the responses in Table 3 are 30 -minute responses, while those in Table 6 are one-day responses. Second, Table 3 uses the on-the-run coupon-bearing 10-year Treasury bond, while Table 6 uses the 10-year zero-coupon yield estimate by Gürkaynak, Sack, and Wright (2007). The latter yield has a longer duration than the coupon-bearing 10-year security and thus should be a better match to the long-term corporate bonds in the Moody's indexes.
} 
Table 6: Estimated Effects of Changes in the Federal Funds Rate, Forward Guidance, and LSAPs on Corporate Bond Yields and Spreads

\begin{tabular}{lcc} 
Corporate & Yields & \multicolumn{2}{c}{ Spreads } \\
Aaa & Baa & Aaa-10-yr. Baa-10-yr.
\end{tabular}

(A) estimated effects of federal funds rate and forward guidance, Jul. 1991-Dec. 2008

$\begin{array}{lcccc}\text { change in federal funds rate } & 0.32 & 0.41 & -0.41 & -0.32 \\ \quad(\text { std. err.) } & (.394) & (.393) & (.384) & (.385) \\ \quad \text { t } \text {-stat. } & {[0.82]} & {[1.05]} & {[-1.08]} & {[-0.84]} \\ \text { change in forward guidance } & 2.08^{* * *} & 1.96^{* * *} & -0.60^{*} & -0.72^{*} \\ \quad \text { (std. err.) } & (.471) & (.459) & (.366) & (.371) \\ \quad \text { t } \text {-stat. } & {[4.41]} & {[4.26]} & {[-1.65]} & {[-1.95]} \\ \text { Regression } R^{2} & .18 & .18 & .04 & .07 \\ \text { \# Observations } & 158 & 158 & 158 & 158\end{array}$

(B) estimated effects of forward guidance and LSAPs, Jan. 2009-Oct. 2015

$\begin{array}{lcccc}\text { change in forward guidance } & 0.48 & -0.51 & -1.64 & -2.63^{* * *} \\ \quad(\text { std. err.) } & (1.002) & (.996) & (1.037) & (1.088) \\ \quad \text { t } \text {-stat. } & {[0.48]} & {[-0.51]} & {[-1.58]} & {[-2.42]} \\ \text { change in LSAPs } & -4.51^{* * *} & -5.25^{* * *} & 3.56^{* * *} & 2.81^{* * *} \\ \quad(\text { std. err. }) & (1.017) & (1.114) & (.977) & (.911) \\ \quad[t \text {-stat. } & {[-4.43]} & {[-4.72]} & {[3.64]} & {[3.09]} \\ \text { Regression } R^{2} & .45 & .50 & .53 & .55 \\ \text { \# Observations } & 55 & 55 & 55 & 55\end{array}$

Coefficients $\beta$ from regressions $\Delta y_{t}=\alpha+\widetilde{F}_{t} \beta+\varepsilon_{t}$, where $t$ indexes FOMC announcements, $y$ denotes the corporate bond yield or spread, $\widetilde{F}$ denotes the monetary policy factors estimated previously, and $\Delta$ is the change in a one-day window bracketing each FOMC announcement. Coefficients are in units of basis points per standard deviation change in the monetary policy instrument. Bootstrapped standard errors in parentheses and $t$-statistics in square brackets; ${ }^{* * *},{ }^{* *}$, and ${ }^{*}$ denote statistical significance at the $1 \%$, $5 \%$, and $10 \%$ levels, respectively. See text for details.

and Vissing-Jorgensen (2011, 2013) and Swanson (2011), who found that the Fed's LSAP programs pushed down Treasury yields more than private-sector yields, presumably because the Fed concentrated many of its purchases on longer-term Treasury bonds in particular. Nevertheless, the effect on corporate yields in Table 6 is larger than those previous studies found - for example, Swanson (2011) estimated corporate yields fall about $4-5$ bp in response to a $\$ 600$ billion LSAP announcement, while the estimates in Table 6 are closer to 11-12bp for the same size operation. One reason for the larger estimates here may be that the Fed's recent LSAP programs often included a substantial quantity of mortgage-backed securities (MBS), while the smaller, 4-5bp 
estimate is for the case of a Treasury-only LSAP. Since corporate bonds are closer substitutes for MBS than they are for Treasuries, we should expect MBS purchases to have a relatively larger effect on corporate yields.

\section{The Persistence of Forward Guidance and LSAP Effects}

The regressions above measure the 30-minute or one-day responses of different yields and asset prices to FOMC announcements. If yields and asset prices are martingales, then these very short-term responses are representative of the responses over longer windows as well. However, some recent studies suggest the effects of unconventional monetary policy may not be persistent. For example, Duffie (2010) cites several examples where large movements of captial (e.g., due to stocks entering or leaving the S\&P500, or auctions of new Treasury securities) can have transitory effects on asset prices that dissipate over a period of time, up to several months in length. The idea is that arbitrage capital can be "slow-moving" and is not reallocated instantaneously to take advantage of asset price distortions caused by idiosyncratic changes in demand or supply for the asset. Fleckenstein, Longstaff, and Lustig (2014) find support for this theory in the pricing of TIPS securities during the 2007-09 global financial crisis.

Taylor (2012) and Woodford (2012) argue against the effectiveness of the Federal Reserve's LSAPs for essentially the same reasons. Although the Fed's announcement of an LSAP causes high-frequency movements in yields or asset prices around the time of the announcement, the argument goes, these changes in risk premia will disappear eventually as arbitrageurs react to the announcement and adjust their positions, but this process takes time because the Fed's expected asset purchases are so large, amounting to hundreds of billions of dollars. The empirical evidence in Wright (2012) supports this view: using a dailiy-frequency VAR, Wright (2012) estimates that the effects of FOMC unconventional monetary policy announcements on U.S. long-term bond yields had a half-life of only about $2-3$ months.

\subsection{Unconstrained $h$-Day Yield Changes}

To examine the persistence of the effects of the FOMC's forward guidance and LSAP announcements, I run a series of regressions at multiple horizons, of the form

$$
y_{t-1+h}=\alpha_{h}+\beta_{h} y_{t-1}+\gamma_{h} \widetilde{F}_{t}+\varepsilon_{t}^{(h)}
$$


where the horizon $h$ is measured in business days, each forecast horizon $h$ is associated with a different regression, $y$ denotes a given bond yield or log asset price, $t$ takes on the values of the dates of FOMC announcements from January 2009 through October 2015, $\widetilde{F}$ denotes the forward guidance and LSAP components of FOMC announcements as estimated above, $\varepsilon_{t}^{(h)}$ is a residual, and $\alpha_{h}, \beta_{h}$, and $\gamma_{h}$ are parameters that may vary across regressions $h$. This is essentially Jordà's (2005) local projections method of estimating impulse response functions, with a lag length of zero for the lagged endogenous variable $y$ on the right-hand side, since I find that additional lags aren't needed. As discussed by Jordà (2005), the direct projections in (3) have several advantages over extrapolating the results of a daily-frequency $\operatorname{VAR}(1)$ as in Wright (2012). In particular, the results of extrapolation compound any errors in the parameter estimates as the horizon $h$ increases, while the local projections method avoids extrapolation and compounding and is thus more robust to model misspecification.

I estimate that the coefficients $\alpha_{h}$ and $\beta_{h}$ are essentially always close to zero and one, respectively, so I impose those restrictions in the analysis. Then (3) is just a regression of the $h$-day difference, $y_{t-1+h}-y_{t-1}$, on the factors $\widetilde{F}_{t}$, on the sample of all 55 FOMC announcements from 2009-15. The estimated coefficients $\hat{\gamma}_{h}$ vary across forecast horizons $h$, so we can plot those coefficients as a function of the horizon $h$ to see whether they tend to diminish as $h$ increases. Of course, for longer horizons $h$, there will also be a greater amount of non-monetary-policy news that impacts yields and asset prices, so the residuals $\varepsilon_{t}^{(h)}$ and standard errors surrounding the coefficient estimates $\hat{\gamma}_{h}$ will tend to be larger.

Figure 2 plots the results of these regressions for 2- and 10-year Treasury yields. The solid blue line in each panel plots the point estimates of $\hat{\gamma}_{h}$ as a function of horizon $h$, and dotted red lines plot bootstrapped \pm 1.96 -standard-error bands around those point estimates (see Appendix B for details).

The estimated effect of a one-standard-deviation change in forward guidance on the 2year Treasury yield is about 3bp on the first day (top-left panel of Figure 2), slightly less than the estimated effect in Table 4 that used intradaily data, and this one-day response is highly statistically significant. For horizons $h$ out to about 50 business days, the point estimates remain between 2.5 and $6 \mathrm{bp}$, and are statistically significant out to horizons of about 35 days. At horizons beyond about 50 days, the point estimates are typically smaller.

The effect of forward guidance on the 10-year Treasury yield (top-right panel of Figure 2) is about $2 \mathrm{bp}$ on the first day, although it is not statistically significant. For horizons out to about 

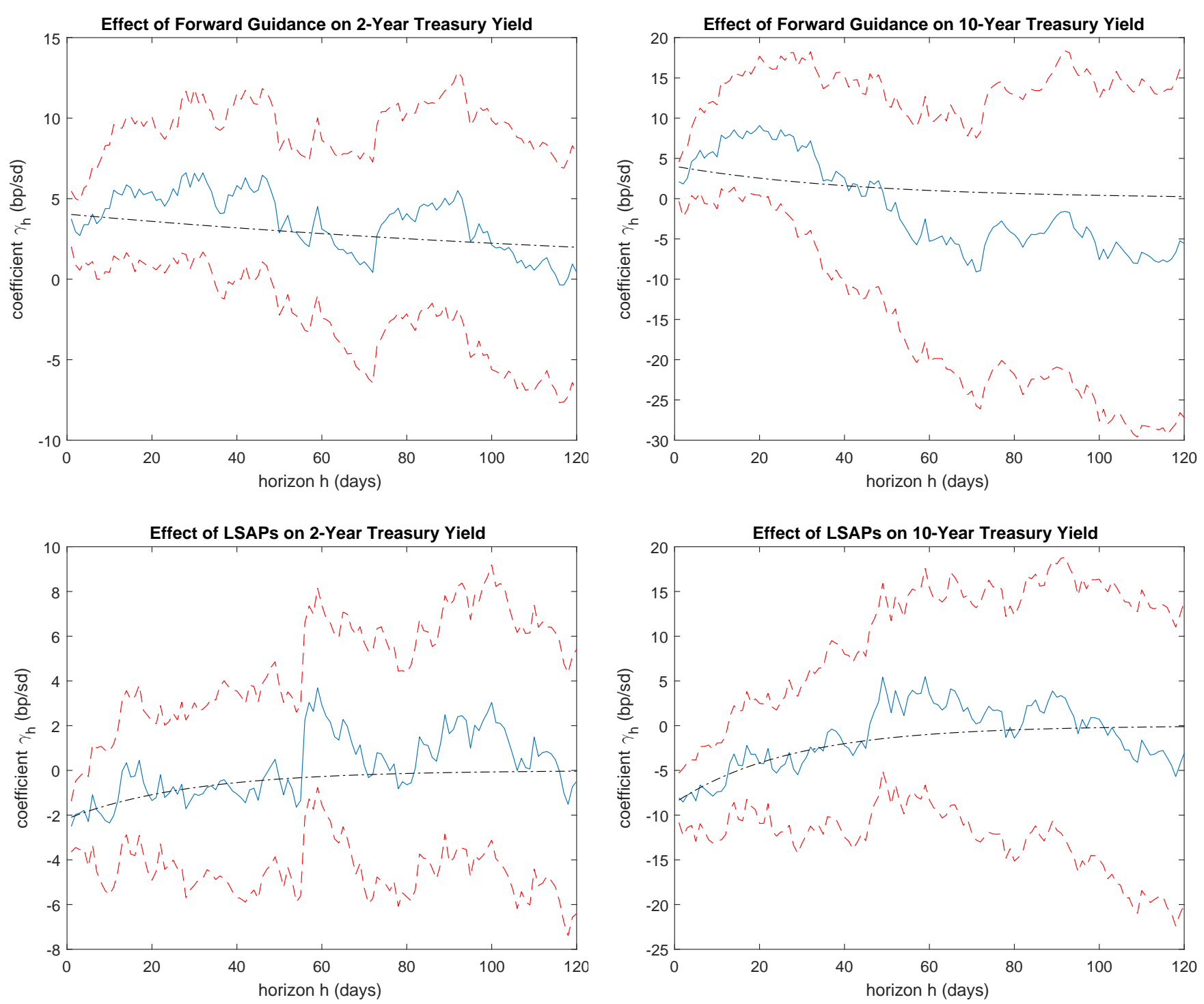

Figure 2. Estimated effects of forward guidance and LSAPs on 2- and 10-year zero-coupon Treasury yields, for different horizons $h$ ranging from 1 to 120 business days. Estimated coefficients $\hat{\gamma}_{h}$ (solid blue line) and bootstrapped \pm 1.96 -standard-error bands (dashed red lines) are from regressions $y_{t-1+h}-y_{t-1}=$ $\gamma_{h} \widetilde{F}_{t}+\varepsilon_{t}^{(h)}$. Restricted coefficient estimates $\gamma_{h}=a e^{-b(h-1)}$ (dash-dotted black lines) are from the same set of regressions estimated jointly via nonlinear least squares. See text for details.

35 days, the effect is actually somewhat larger, around 5-8bp, and is sometimes statistically significant. After about 40 days, the effects of forward guidance on the 10-year yield are close to zero.

The effect of a one-standard-deviation increase in LSAPs on the 2-year Treasury yield (bottom-left panel of Figure 2) is about -2.5bp on the first day, and this effect is statistically significant. $^{26}$ However, the effect diminishes with the horizon $h$, fluctuating around zero after

\footnotetext{
${ }^{26}$ The estimated effect in Table 4 is essentially zero, but that estimate is for an on-the-run (i.e., most recently
} 
about 55 days. The standard error bands are somewhat narrower than for forward guidance. For the 10-year Treasury yield in the bottom-right panel, the estimated effect is about -8bp on impact, and again the effect diminishes almost monotonically over time, fluctuating around zero after about 50 days.

\subsection{Persistence Estimates}

To estimate the degree of attenuation in these figures, and the statistical significance of that attenuation, I re-estimate regressions (3) imposing that the coefficients $\gamma_{h}$ have an exponentially decaying functional form,

$$
\gamma_{h}=a e^{-b(h-1)}
$$

where $a$ and $b$ are parameters, with $a$ denoting the impact effect and $b$ the exponential decay rate. The idea is essentially the same as Barnichon and Brownlees' (2018) "smooth local projections": unrestricted local projections can lead to excess variability of the estimates, but this variability can be reduced by imposing prior information on the impulse responses, in this case smoothness and an exponentially decaying functional form.

I stack the regressions (3) into a single system, impose the restriction (4) on the coefficients $\gamma_{h}$, and estimate the parameters $a$ and $b$ in a single step via weighted nonlinear least squares. $^{27}$ The dash-dotted black lines in Figure 2 depict the results of this restricted estimation.

Table 7 reports the estimated values of $a$ and $b$ for the effects of forward guidance and LSAPs on the 2- and 10-year Treasury yields, along with bootstrapped $t$-statistics. The impact effects $a$ in the top panel are all statistically significant, consistent with the earlier results above. A standard martingale view of asset price responses would imply that $b=0$, but in Table 7 , the decay rates $b$ are typically larger than zero, with half-lives of about 20 business days for LSAPs, and 30 and 110 business days for forward guidance on the 10- and 2-year Treasury yields, respectively. However, none of these decay rates is statistically significant.

issued, most liquid, and most heavily traded) coupon-bearing 2-year Treasury, while the estimates in Figure 3 are for a zero-coupon 2-year Treasury, which has a longer Macauley duration. Since the effects of LSAPs generally increase with duration, the effect on the zero-coupon 2-year Treasury is larger. Zero-coupon yields are from the Gürkaynak et al. (2007) database and keep the maturity constant even as the horizon $h$ and time $t$ change.

27 The observations for each horizon $h$ are weighted by $\sigma_{h}^{-1}$, where $\sigma_{h}$ denotes the estimated variance of the residuals for the unrestricted horizon $h$ regression (3). I also impose two restrictions on the estimation: First, the coefficient $a$ cannot be more than $25 \%$ greater or less than the average unconstrained effect $\gamma_{h}$ over the first 5 days. Second, the coefficient $b \geq 0$. These restrictions prevent the estimation from picking values of $a$ and $b$ that are implausible a priori. Finally, the regressions in (3)-(4) are stacked and run out to a 180-business-day horizon $h$, to help estimate the decay parameter $b$. 
Table 7: Estimated Persistence Coefficients

\begin{tabular}{ccc} 
Forward Guidance & \multicolumn{2}{c}{ LSAPs } \\
$a$ & $b$ & $a$
\end{tabular}

Jan. 2009-Oct. 2015:

$\begin{array}{ccccc}\text { 2-year Treasury yield } & 4.0^{* * *} & .006 & -2.2^{* * *} & .034 \\ {[t \text {-stat. }} & {[4.12]} & {[0.25]} & {[-3.00]} & {[0.27]} \\ \text { 10-year Treasury yield } & 4.0^{* *} & .023 & -8.6^{* * *} & .036 \\ {[t \text {-stat. }} & {[2.22]} & {[1.17]} & {[-6.05]} & {[1.31]}\end{array}$

Jan. 2009-Oct. 2015, excluding March 18, 2009:

$\begin{array}{ccccc}\text { 2-year Treasury yield } & 4.1^{* * *} & .007 & -0.3 & 18.07 \\ \text { [t-stat.] } & {[4.28]} & {[0.51]} & {[-0.50]} & {[1.43]} \\ \text { 10-year Treasury yield } & 3.6^{*} & 0.022 & -4.9^{* * *} & 0.001 \\ \text { [t-stat. } & {[1.85]} & {[1.52]} & {[-2.80]} & {[0.01]}\end{array}$

Coefficients $a$ and $b$ for restriction $\gamma_{h}=a e^{-b(h-1)}$ in regressions (3), estimated via nonlinear least squares. Bootstrapped $t$-statistics in square brackets; ${ }^{* * *},{ }^{* *}$, and ${ }^{*}$ denote statistical significance at the $1 \%, 5 \%$, and $10 \%$ levels, respectively. See text for details.

Although the largest estimated decay rates in Table 7 are for LSAPs, it's important to note that those estimates are very sensitive to whether or not the extremely influential March 18, 2009, FOMC announcement is included in the analysis. (Recall that announcement was about 5.5 standard deviations, corresponded to over $\$ 1.1$ trillion of new long-term bond purchases and implicitly raised the possibility that there could be additional such operations in the future.) The bottom panel of Table 7 reports results for the same regressions, excluding that one observation from the sample. In this case, the results for forward guidance are essentially unchanged, while the results for LSAPs no longer show any evidence of fading out over time. ${ }^{28}$

Figure 3 repeats the analysis in Figure 2, but excluding the March 18, 2009, observation. The results for forward guidance are essentially identical to Figure 2 and are not reported, but the results for LSAPs are very different: for the 2-year Tresury yield, the effects are no longer significant at any horizon, and for the 10-year yield, there is no longer any appearance of attenuation. The effects of LSAPs look completely persistent.

For reference, Figure 4 reports the behavior of Treasury yields around the March 18, 2009, announcement. Yields of all maturities fell dramatically on the day of the announcement, but 5- and 10-year yields began to drift back up over the ensuing weeks, erasing the entire decline

\footnotetext{
${ }^{28}$ The impact effect of LSAPs on the 2-year Treasury yield is no longer significant when the March 18, 2009, observation is dropped, which implies that the decay parameter $b$ is no longer well identified and results in the large numerical value in the table. The impact effect on the 10-year Treasury yield remains highly statistically significant, however, albeit with a smaller magnitude.
} 

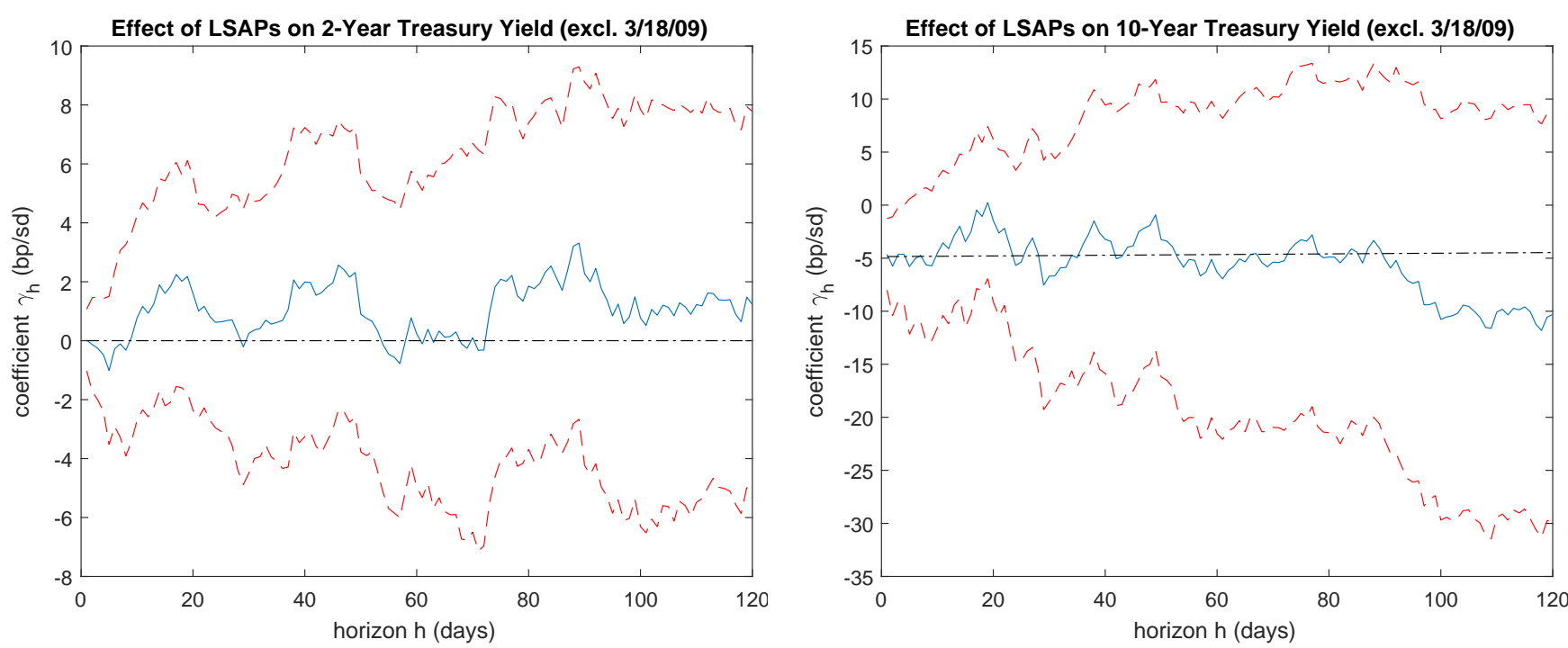

Figure 3. Estimated effects of LSAPs on 2- and 10-year zero-coupon Treasury yields for different horizons $h$, excluding the large and influential March 18, 2009, FOMC announcement. (Results for forward guidance are essentially identical to Figure 2 and are not reported.) See notes to Figure 2 and text for details.

in long-term yields by about the 30th business day following the announcement. The very large size of the LSAP factor for this FOMC announcement gives these responses a very large weight in the regression analysis above.

Thus, in contrast to Wright (2012), I find relatively little evidence that the effects of the Fed's unconventional monetary policy announcements died out over time. Although the point estimates for forward guidance and LSAPs in Table 7 do suggest some attenuation, those estimates are not statistically significant. Moreover, for LSAPs, there is no evidence of attenuation once the very influential March 2009 FOMC announcement is dropped from the analysis. ${ }^{29}$

\section{Effects of Forward Guidance and LSAPs on Interest Rate Uncertainty}

Unconventional monetary policy could also have substantial effects on interest rate uncertainty. Bernanke (2013) emphasizes that a major goal of forward guidance was to reduce financial market uncertainty about the path of the federal funds rate, not just financial market expectations about that path. In this section, I investigate whether the FOMC's forward guidance announcements achieved this additional goal.

I also investigate whether LSAP as well as forward guidance announcements had effects on interest rate uncertainty. The effect of LSAPs on uncertainty is ambiguous and is ultimately an

\footnotetext{
${ }^{29}$ In Swanson (2017), I also estimate the persistence of the effects of federal funds rate changes in the pre-ZLB period, and show that those effects also seem to be completely persistent.
} 


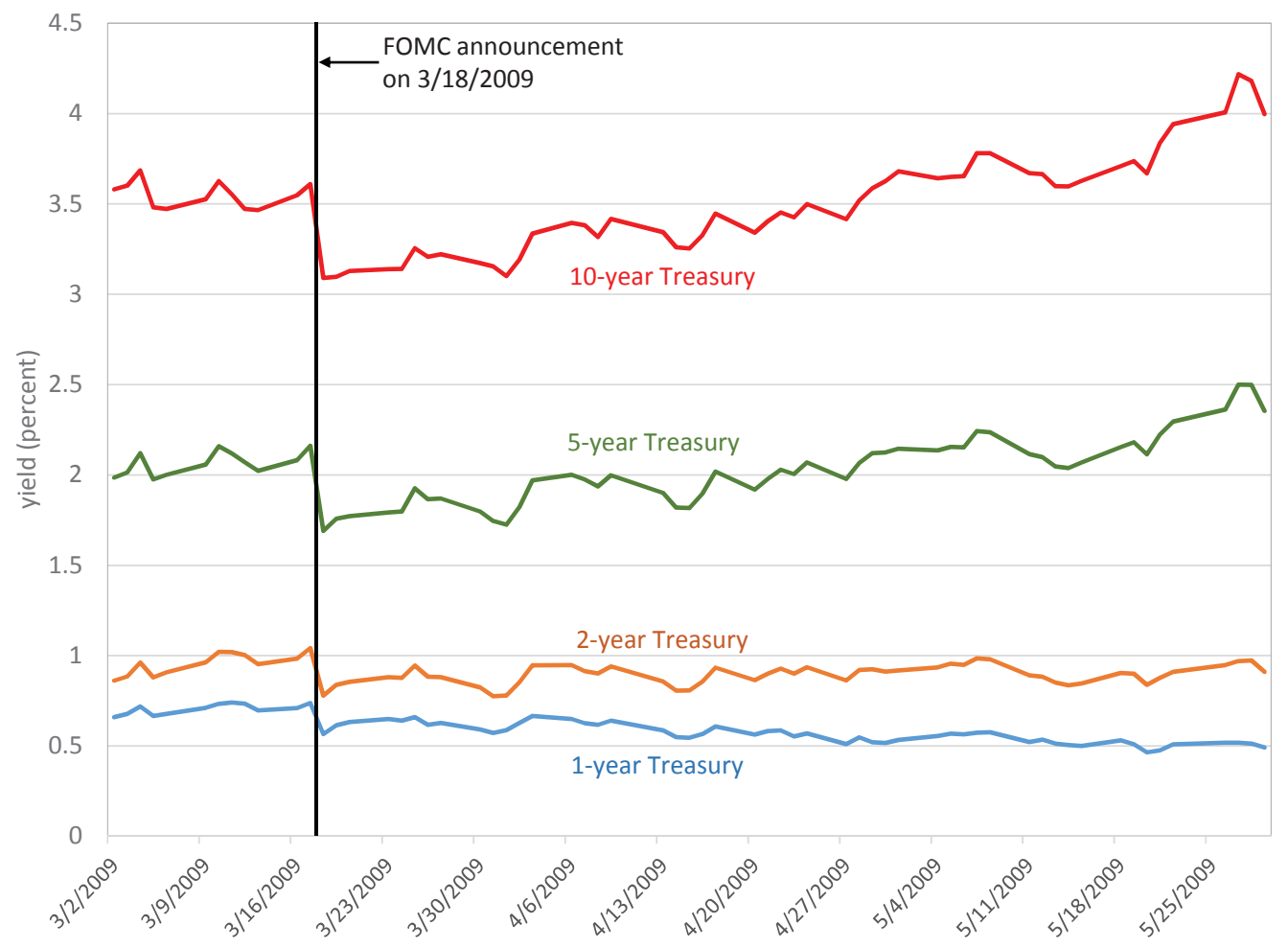

Figure 4. 1-, 2-, 5-, and 10-year zero-coupon Treasury yields from March 1 to May 31, 2009. See text for details.

empirical question: on one hand, if LSAPs are a new source of shocks to long-term bond yields, that could increase uncertainty about those yields; alternatively, LSAPs could reduce uncertainty if they tended to be implemented in response to increases in long-term yields, because then LSAPs would be a stabilizing force.

To measure uncertainty about the federal funds rate over the next several months or quarters, I use Eurodollar options with five quarters to expiration, as in Swanson and Williams (2014). These data are available at daily frequency with a range of strike prices, which can be used to estimate the entire distribution of the federal funds rate in five quarters' time. ${ }^{30}$ Following Swanson and Williams (2014), I use the distance between the $80^{\text {th }}$ and $20^{\text {th }}$ percentiles of that distribution on any given day as a measure of uncertainty on that day about the federal funds rate five quarters ahead.

\footnotetext{
${ }^{30}$ I don't need to assume normality for these distributions because we observe option prices for multiple strikes. On each day from January 2008 through December 2015, I use the range of available Eurodollar option put and call prices with five quarters to expiration to estimate the implied distribution of the spot 3-month Eurodollar rate in five quarters' time, using a flexible functional form. Eurodollar options are the most liquid options on a short-term interest rate and thus provide the best measure of the distribution of possible short-term interest rate outcomes. I use the spread between overlapping federal funds futures and Eurodollar futures rates at a one-year horizon to convert these implied distributions for the 3-month Eurodollar rate into an implied distribution for the federal funds rate. These probability estimates ignore risk premia and thus represent implied risk-neutral probabilities.
} 


\section{Table 8: Estimated Effects of Forward Guidance and LSAPs on Monetary Policy UnCertainty, 2009-2015}

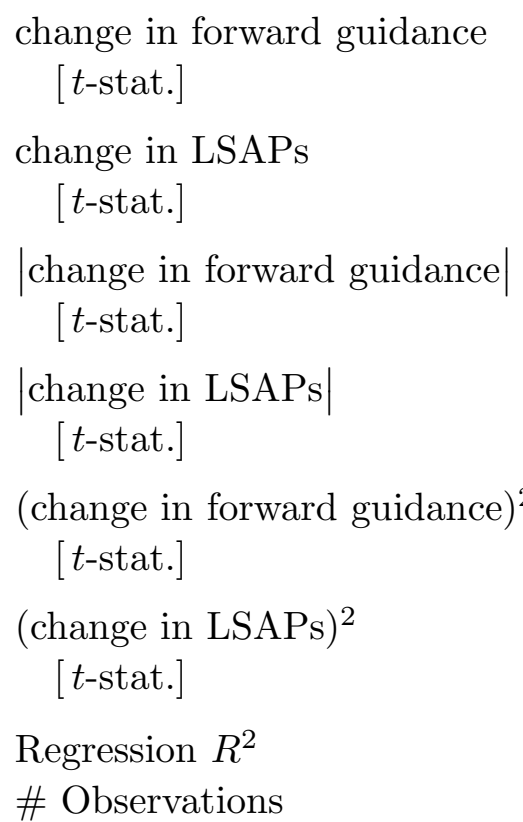

$\begin{array}{ccc}4.21^{* * *} & 3.78^{* *} & 3.55^{* *} \\ {[2.64]} & {[2.35]} & {[2.11]} \\ 1.14 & 1.58 & 1.07 \\ {[0.95]} & {[1.02]} & {[0.60]} \\ - & -2.09 & - \\ - & {[-1.07]} & - \\ - & -0.38 & - \\ - & {[-0.23]} & - \\ - & - & -1.03 \\ - & - & {[-0.99]} \\ - & - & 0.06 \\ - & - & {[0.15]} \\ .15 & .17 & .17 \\ 55 & 55 & 55\end{array}$

Coefficients $\beta$ from regressions of one-day changes in monetary policy uncertainty on forward guidance and LSAP factors, nonlinear transformations of those factors, and a constant (not reported). Monetary policy uncertainty is the interquintile range (in bp) for the federal funds rate distribution 5 quarters ahead, from Eurodollar options. Bootstrapped $t$-statistics in square brackets; ${ }^{* * *}$ and ${ }^{* *}$ denote statistical significance at the $1 \%$ and $5 \%$ levels, respectively. See text for details.

The first column of Table 8 reports results from regression (3) with monetary policy uncertainty as the dependent variable $y$. In response to a one-standard-deviation increase in forward guidance, monetary policy uncertainty increases by about 4bp (as measured by the interquintile range in the options-implied PDF), and this change is highly statistically significant. Thus, the data support Bernanke's (2013) stated goal that reductions in forward guidance by the FOMC should reduce financial market uncertainty about the path of the federal funds rate. In contrast to forward guidance, LSAPs have no significant effect on monetary policy uncertainty on impact.

Of course, one might expect monetary policy uncertainty to decrease in response to any forward guidance announcement by the Fed, regardless of whether that announcement is positive or negative (i.e., a tightening or an easing). To investigate this possibility, the second column of Table 8 includes the absolute values of the forward guidance and LSAP factors in regression (3). Surprisingly, the coefficients on these absolute values are not statistically significant while the coefficient on the forward guidance announcement itself is essentially unchanged. As an alternative, the third column of Table 8 includes squared forward guidance and LSAP factors instead, 

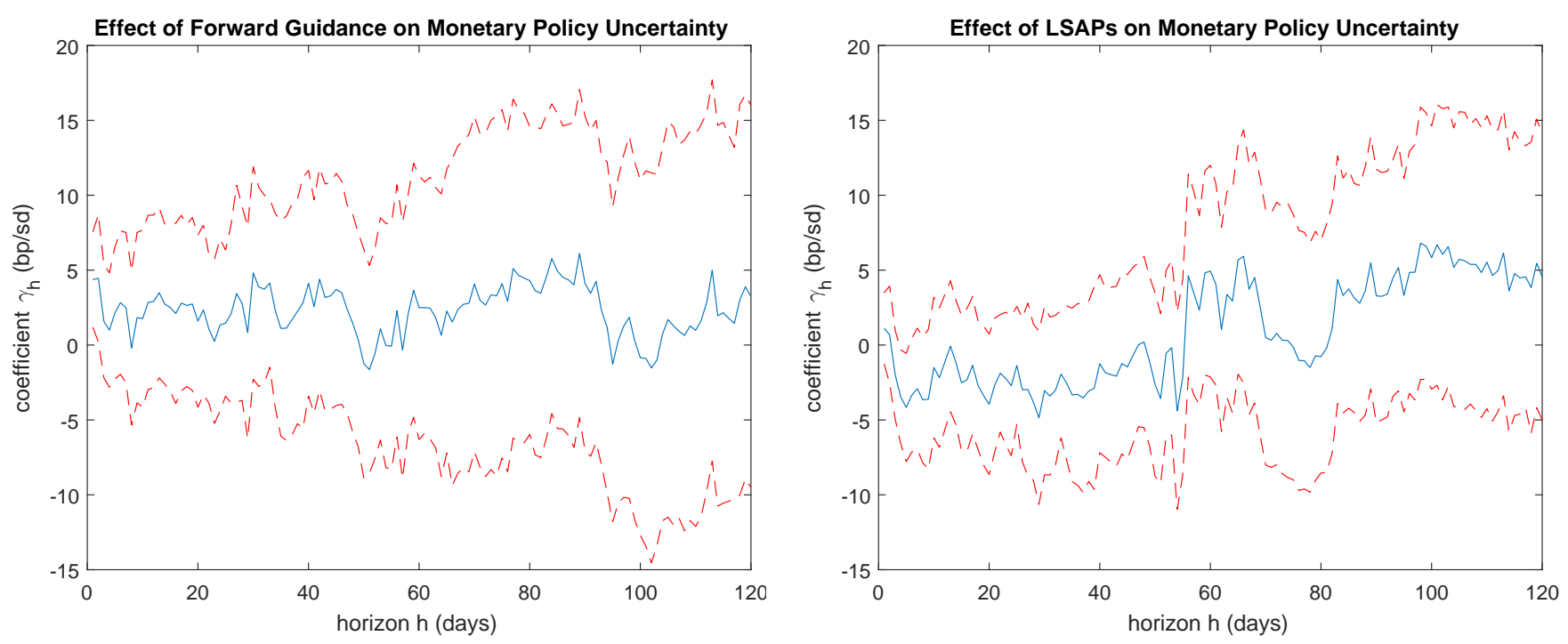

Figure 5. Estimated effects of forward guidance and LSAPs on monetary policy uncertainty, measured as the distance (in bp) between the $80^{\text {th }}$ and $20^{\text {th }}$ percentiles of the PDF for the federal funds rate 5 quarters ahead, implied by Eurodollar options. See notes to Figure 2 and text for details.

with similar results - the nonlinear terms are not statistically significant, while the results for the linear forward guidance factor are essentially unchanged.

The results in Table 8 show that, between 2009 and 2015, forward guidance easings reduced monetary policy uncertainty, while forward guidance tightenings increased that uncertainty. That last result might seem surprising at first, but is intuitive if we think about the interaction of monetary policy uncertainty with the zero lower bound. Throughout 2009-15, the federal funds rate was essentially zero, a level that the FOMC regarded as its effective lower bound. Thus, financial markets viewed a negative federal funds rate as virtually a measure-zero event. Forward guidance easings during this period reduced the mean level of the expected federal funds rate over the next several quarters, and thus compressed the distribution of the future federal funds rate against the zero lower bound. This compression mechanically reduces measured monetary policy uncertainty. In contrast, forward guidance tightenings increased the mean level of the expected federal funds rate and thus reduced the extent to which the future federal funds rate distribution was compressed against the zero lower bound. This expansion of the federal funds rate distribution away from the ZLB mechanically increases measured monetary policy uncertainty. The results in Table 8 are consistent with these mechanical effects of forward guidance on uncertainty being an important driver of those uncertainty results.

Figure 5 examines the persistence of these uncertainty effects. Since the nonlinear terms in Table 8 were not statistically significant, the regressions in Figure 5 consider only the linear 

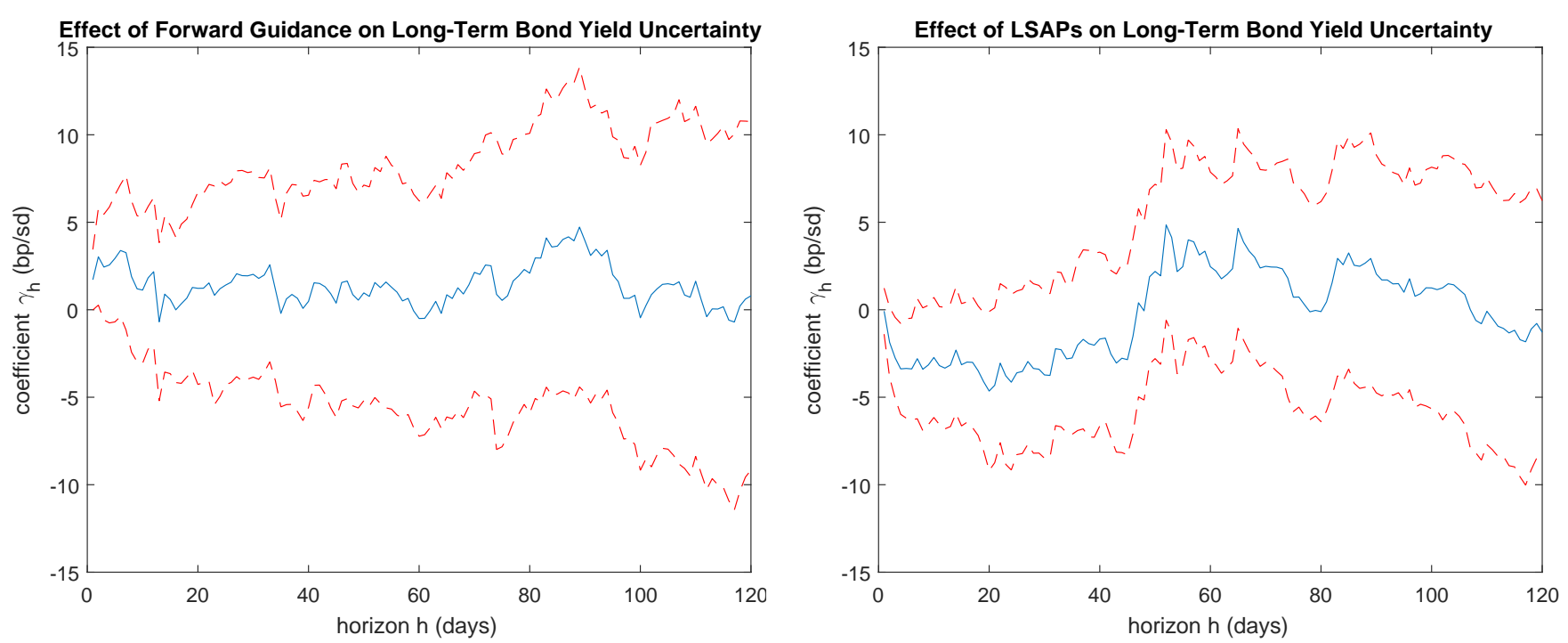

Figure 6. Estimated effects of forward guidance and LSAPs on long-term bond yield uncertainty, as measured by the Bank of America/Merrill Lynch MOVE index of implied volatility (in bp/year) from options on Treasury securities. See notes to Figure 2 and text for details.

terms, as in previous figures. After the first day, there is little evidence that the effect of forward guidance dies out over time, although the standard errors grow so that the effect is not statistically significant after about 2 days. For LSAPs, interestingly, there is no effect on impact but the effect grows substantially over the next few days and becomes statistically significant. A onestandard-deviation increase in LSAPs was typically followed by a $2-5 \mathrm{bp}$ decline in monetary policy uncertainty for most of the next 50 days. This finding seems in line with the discussion in Woodford (2012), Krishnamurthy and Vissing-Jorgensen (2011, 2013) and Bauer and Rudebusch (2014), that one channel through which LSAPs affected financial markets was by signaling the FOMC's commitment to keep the federal funds rate low for an extended period. Thus, even though my results in Tables 2 and 3 reject the hypothesis that LSAPs work entirely through the signaling channel, my results here do suggest that LSAPs have significant signaling effects.

Figure 6 plots analogous results for the Bank of America/Merrill Lynch MOVE index of long-term bond yield uncertainty. The MOVE index is a composite of implied volatility on U.S. Treasury bonds with 2, 5, 10, and 30 years to maturity, measured using options on these securities, with most of the weight on the 5- and 10-year maturities. Overall, the results in Figure 6 look very similar to those in Figure 5 for shorter-term interest rate uncertainty: An increase in forward guidance raises longer-term bond yield uncertainty by a small amount, but the effect is not statistically significant and declines to zero after a few days. An increase in LSAPs, on the other hand, has essentially no effect on longer-term bond yield uncertainty on impact, but then 
leads to a statistically significant decline in that uncertainty by about 3.5bp over the next few days, and this effect persists for about 45 days (although it loses its significance).

Far from increasing longer-term bond yield uncertainty, an increase in LSAPs by the Fed seems to have had a stabilizing effect on longer-term bond yields. This would be the case, for example, if the FOMC's LSAP operations were conducted in such a way as to "push back" against movements in long-term interest rates.

Finally, I investigate the effects of forward guidance and LSAPs on stock market uncertainty, as measured by the VIX, but find no statistically significant effects at any horizon (results not reported).

\section{Conclusions}

I extend the methods of Gürkaynak, Sack, and Swanson (2005) to separately identify the forward guidance and large-scale asset purchase component of every FOMC announcement of the U.S. zero lower bound period, January 2009 to October 2015. I show that this identification is quite robust and that my estimated forward guidance and LSAP announcements agree with observable characteristics of notable FOMC statements.

I separately estimate the effects of forward guidance and LSAPs on a variety of assets, including Treasuries, stocks, exchange rates, corporate bonds, and interest rate options (to measure uncertainty). Both forward guidance and LSAPs had substantial and highly statistically significant effects on medium-term Treasury yields, with magnitudes comparable to the effects of changes in the federal funds rate before the zero lower bound (as measured by their asset price effects per standard deviation change in each policy). Thus, I find that both of these unconventional monetary policies were effective policy instruments, about as effective as conventional monetary policy.

Forward guidance was more effective than LSAPs at moving shorter-term Treasury yields and stock prices, while LSAPs were more effective than forward guidance and the federal funds rate at moving longer-term Treasury yields, corporate bonds, and interest rate uncertainty. To the extent that monetary policy affects the real economy through changes in private-sector interest rates like corporate bond yields, this suggests that LSAPs were more effective than forward guidance at stimulating the real economy. LSAPs were also more effective at reducing interest rate uncertainty, which may also stimulate the real economy (e.g., Bloom, 2009). 
I find no significant evidence that either forward guidance or LSAPs had effects that died out over time. I estimate that the effects of LSAP anouncements were completely persistent, with no tendency to die out over the next several months, with the exception of the very influential "QE1" announcement in March 2009. After that particular announcement, long-term bond yields fell sharply but then rebounded over the next two months as financial markets turned around. Given that financial markets were functioning very poorly in March 2009, and the QE1 announcement was so large, the financial market responses to that announcement may not be representative of LSAP effects more generally.

I estimate that the effects of forward guidance were somewhat less persistent, with a half-life of about 1-4 months, but those estimates are not statistically significant. To some extent, we should expect the effects of forward guidance to die out gradually over time, since the FOMC's forward guidance announcements over this period had a typical horizon of several quarters or less. My point estimates are generally consistent with this fact.

Overall, I find there is relatively little reason for the Federal Reserve to raise its inflation target to avoid hitting the zero lower bound in the future, because the Fed has other monetary policy tools available.

Going forward, there are many important issues that call for further exploration. First and foremost, estimating the effects of forward guidance and LSAPs on macroeconomic variables such as the unemployment rate should be a top priority for future research-after all, the FOMC's stated goal in pursuing these unconventional policies was to boost the economy. Measuring the response of macroeconomic rather than financial variables to monetary policy announcements is difficult, however, because of the lower frequency and longer response lags of macroeconomic variables to those announcements. A second important avenue for future research is to study the effects of unconventional monetary policies in other economies, especially since the zero lower bound period in the U.S. has ended. The methods of the present paper should be very helpful for studying the effects of unconventional monetary policies in these other economies as well as in the U.S. 


\section{Appendix A: Details of Identifying Restrictions}

As discussed in Section 2, the factor model (1) is not uniquely identified by the data. Here I provide the details of the identifying restrictions in Section 2.

Given the $T \times n$ matrix $X$ of $n$ asset price responses to the $T$ FOMC announcements in my sample, I first demean and scale each column of $X$ to have zero mean and unit variance. I then extract the first three principal components of the standardized matrix to estimate the three latent factors that explain a maximal fraction of the variance of the (standardized) data. Let $F$ denote the $T \times 3$ matrix of these first three principal components, and $\Lambda$ the $3 \times n$ matrix of loadings of the data $X$ on $F$ (cf. eq. (1)).

It's straightforward to show that a $3 \times 3$ orthogonal matrix $U$ is uniquely determined by three parameters. Thus, we require three identifying restrictions to uniquely identify the rotation $U$ that maps the principal components $F$ into three factors $F^{*} \equiv F U$ that have a structural interpretation as 1) the surprise change in the federal funds rate target, 2) the surprise change in forward guidance, and 3) the surprise change in LSAPs.

As discussed in Section 2, my first two identifying assumptions are that LSAPs and forward guidance have no effect on the current federal funds rate. These two zero restrictions can be written as

$$
U^{\prime} \Lambda_{1}=\left[\begin{array}{l}
\cdot \\
0 \\
0
\end{array}\right]
$$

where $\Lambda_{1}$ denotes the first column of $\Lambda$, the loadings of the current-month federal funds rate on the three factors $F$. Letting $U_{i}$ denote the $i$ th column of $U$, these restrictions correspond to $\Lambda_{1}^{\prime} U_{2}=0$ and $\Lambda_{1}^{\prime} U_{3}=0$. Effectively, these two restrictions imply that only the first factor has any systematic effect on the federal funds rate.

My third identifying restriction is that the variance of the LSAP factor is as small as possible over the sample from 1991 to 2008 . The LSAP factor is given by $F U_{3}$, so this restriction amounts to minimizing $U_{3}^{\prime}\left(F^{\text {pre }}\right)^{\prime} F^{\text {pre }} U_{3}$, where $F^{\text {pre }}$ denotes the $158 \times 3$ matrix of values of $F$ from $1990-2008$. This is a constraint on $U_{3}$ that does not directly affect $U_{1}$ or $U_{2}$, except via the orthogonality conditions between the columns of $U$.

Computationally, I implement these three restrictions as follows. First, I implement restrictions one and three above in one step as a quadratic minimization problem subject to a linear constraint: I temporarily ignore the unit length requirement on $U_{3}$ and normalize the third element of $U_{3}$ to unity; ${ }^{31}$ I then minimize

$$
\left[\begin{array}{lll}
u_{13} & u_{23} & 1
\end{array}\right]\left(F^{\mathrm{pre}}\right)^{\prime} F^{\mathrm{pre}}\left[\begin{array}{c}
u_{13} \\
u_{23} \\
1
\end{array}\right],
$$

subject to $\Lambda_{1}^{\prime}\left[\begin{array}{lll}u_{13} & u_{23} & 1\end{array}\right]^{\prime}=0$, where this last constraint ensures the minimization respects the first identifying assumption. After computing the minimizing vector $\left[\begin{array}{lll}u_{13} & u_{23} & 1\end{array}\right]^{\prime}$, I rescale it to have unit length and call the resulting vector $U_{3}$.

To implement the second identifying restriction, I again temporarily ignore the unit length requirement on $U_{2}$ and normalize its third element to unity. I then solve the equation

$$
\left[\begin{array}{c}
\Lambda_{1}^{\prime} \\
U_{3}^{\prime}
\end{array}\right]\left[\begin{array}{c}
u_{12} \\
u_{22} \\
1
\end{array}\right]=\left[\begin{array}{l}
0 \\
0
\end{array}\right]
$$

for $u_{12}$ and $u_{22}$, which ensures that $\left[\begin{array}{lll}u_{12} & u_{22} & 1\end{array}\right]^{\prime}$ satisfies the identifying restriction and is orthogonal to $U_{3}$. I then rescale the vector $\left[\begin{array}{lll}u_{12} & u_{22} & 1\end{array}\right]^{\prime}$ to have unit length and call the result $U_{2}$.

\footnotetext{
${ }^{31}$ Note that there is nothing special about the third element here or in any of the normalizations below-if the third element happens to be close to zero, then the first or second element can be normalized to unity instead.
} 
Finally, I compute $U_{1}$ by an analogous procedure, normalizing the third element of $U_{1}$ to unity, solving the equation

$$
\left[\begin{array}{c}
U_{2}^{\prime} \\
U_{3}^{\prime}
\end{array}\right]\left[\begin{array}{c}
u_{11} \\
u_{12} \\
1
\end{array}\right]=\left[\begin{array}{l}
0 \\
0
\end{array}\right]
$$

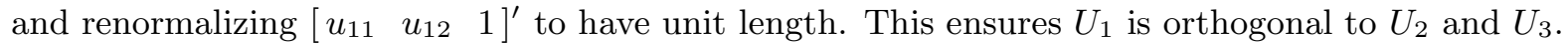

This uniquely identifies $U$ and $F^{*}$ up to a sign normalization for each column. I normalize the sign of the first column of $F^{*}$ to have a positive effect on the current federal funds rate, the second column to have a positive effect on the four-quarter-ahead Eurodollar future contract ED4, and the third column to have a negative effect on the 10-year Treasury yield.

\section{Appendix B: Bootstrap Procedure}

The regressions in Section 4 use the estimated monetary policy factors $\widetilde{F}$ as regressors. Because those regressors are generated from a first-stage estimation procedure, there is some additional uncertainty regarding those variables that would not be present if they were directly observed. Traditional OLS or heteroskedasticity-consistent standard errors do not take this extra sampling uncertainty into account and thus are not correct in general (e.g., Pagan, 1984).

To address this problem, I compute the standard errors in Section 4 by boostrapping, as follows. I first write the $213 \times 8$ matrix of FOMC announcement responses $X$ in terms of the estimated factor model $X=F \Lambda+\varepsilon$, as in Section 2. For each bootstrap sample $i$, I draw 213 random numbers $r_{j}^{(i)}, j=1, \ldots, 213$, between 1 and 213, with replacement. Bootstrap sample $X^{(i)}$ is then defined to be $F \Lambda+\varepsilon^{(i)}$, where the $j$ th row of $\varepsilon^{(i)}$ is given by the $r_{j}^{(i)}$ th row of the original $\varepsilon$. I repeat this procedure 10,000 times to generate bootstrap samples $X^{(i)}, i=1, \ldots, 10,000$. For each boostrap sample $i$, I impose the three identifying assumptions in Section 2 to compute the synthetic structural factors $\widetilde{F}^{(i)}$.

Similarly, for each left-hand side variable $y$ in Section 4, I take the residuals from the original regression $y=\alpha+\beta \widetilde{F}+\eta$ and define the bootstrap vector $y^{(i)}$ to be $\alpha+\beta \widetilde{F}+\eta^{(i)}$, where the $j$ th element of $\eta^{(i)}$ is given by the $r_{j}^{(i)}$ th element of the original $\eta$. For each bootstrap sample $i$, I run the regression $y^{(i)}=\alpha^{(i)}+\beta^{(i)} \widetilde{F}^{(i)}+\nu^{(i)}$ and store the estimated parameters $\alpha^{(i)}$ and $\beta^{(i)}$. The boostrapped standard errors for $\beta$ in Section 4 are computed from the empirical distribution of the $\beta^{(i)}$.

Note that this samples the residuals $\varepsilon$ and $\eta$ with replacement rather than the raw underlying data $X$ and $y$. If we were to sample the observations $X$ and $y$ directly, we would end up with many bootstrap samples that have multiple occcurrences of the large "QE1" announcement by the Fed, and many other bootstrap samples that have no such occurrences. In actuality, the Fed made one "QE1" announcement, and we are interested in the standard errors of our coefficients $\beta$ conditional on that fact. By sampling the residuals $\varepsilon$ and $\eta$, we preserve that feature of the data and compute the standard errors we are interested in.

Bootstrapped standard errors in Section 5 are computed in esssentially the same way. The bootstrap samples $X^{(i)}$ are the same, and for each horizon $h$, the left-hand side variables $\Delta_{h} y_{t-1} \equiv y_{t+1-h}-y_{t-1}$ are sampled in the same way as above. That is, I take the residuals from the original regression $\Delta_{h} y=$ $\alpha_{h}+\beta_{h} \widetilde{F}+\eta_{(h)}$ and define the bootstrap vector $\left(\Delta_{h} y\right)^{(i)}$ to be $\alpha_{h}+\beta_{h} \widetilde{F}+\eta_{(h)}^{(i)}$, where the $j$ th element of $\eta_{(h)}^{(i)}$ is given by the $r_{j}^{(i)}$ th element of the original $\eta_{(h)}$. For each bootstrap sample $i$, I run the regression $\left(\Delta_{h} y\right)^{(i)}=\alpha_{h}^{(i)}+\beta_{h}^{(i)} \widetilde{F}^{(i)}+\nu_{(h)}^{(i)}$ and store the estimated parameters $\alpha_{h}^{(i)}$ and $\beta_{h}^{(i)}$. The boostrapped standard errors for each $\beta_{h}$ in the figures in Section 5 are computed from the empirical distribution of the $\beta_{h}^{(i)}$.

Finally, bootstrapped standard errors in Section 6 are computed in the same way as in Sections 4 and 5 . 


\section{References}

Ball, Laurence (2014). "The Case for a Long-Run Inflation Target of Four Percent," IMF Working Paper 14/92.

Barnichon, Regis, and Christian Brownlees (2018). "Impulse Response Estimation by Smooth Local Projections," Review of Economics and Statistics (forthcoming).

Bauer, Michael, and Glenn Rudebusch (2014). "The Signaling Channel for Federal Reserve Bond Purchases," International Journal of Central Banking 10, 233-289.

Bernanke, Ben (2013). "Communication and Monetary Policy," speech at the National Economists Club Annual Dinner, Herbert Stein Memorial Lecture, November 19, 2013, Washington DC, available at http://www.federalreserve.gov/newsevents/speech/bernanke20131119a.htm

Blanchard, Olivier, Giovanni Dell'Ariccia, and Paolo Mauro (2010). "Rethinking Macroeconomic Policy," IMF Staff Position Note 10/03.

Bloom, Nicholas (2009). "The Impact of Uncertainty Shocks," Econometrica 77, 623-685.

Campbell, Jeffrey, Charles Evans, Jonas Fisher, and Alejandro Justiniano (2012). "Macroeconomic Effects of Federal Reserve Forward Guidance," Brookings Papers on Economic Activity Spring, 1-53.

Cragg, John, and Stephen Donald (1997). "Inferring the Rank of a Matrix," Journal of Econometrics $76,223-250$.

D'Amico, Stefania, William English, David Lopez-Salido, and Edward Nelson (2012). "The Federal Reserve's Large-Scale Asset Purchase Programmes: Rationale and Effects," Economic Journal 122, F415-F446.

Duffie, Darrell (2010). "Presidential Address: Asset Price Dynamics with Slow-Moving Capital," Journal of Finance 55 (4), 1237-1267.

Fleckenstein, Matthias, Francis Longstaff, and Hanno Lustig (2014). "The TiPS-Treasury Bond Puzzle," Journal of Finance 69 (5), 2151-2197.

Forbes (2010). "Bernanke Runs Up the Sails for QE2," by Fontevecchia, Agustino, October 15, 2010, http://www.forbes.com/2010/10/15/bernanke-speech-deflation-equities-markets-housing.html.

Gagnon, Joseph, Matthew Raskin, Julie Remache, and Brian Sack (2011). "The Financial Market Effects of the Federal Reserve's Large-Scale Asset Purchases," International Journal of Central Banking 7, 3-43.

Gertler, Mark, and Peter Karadi (2015). "Monetary Policy Surprises, Credit Costs, and Economic Activity," American Economic Journal: Macroeconomics 7, 44-76.

Gilchrist, Simon, Vivien Yue, and Egon Zakrajsek (2018). "US Monetary Policy and International Bond Markets," Federal Reserve Finance and Economics Discussion Series 2018-014.

Gürkaynak, Refet, Brian Sack, And Eric Swanson (2005). "Do Actions Speak Louder than Words? The Response of Asset Prices to Monetary Policy Actions and Statements," International Journal of Central Banking 1, 55-93.

Gürkaynak, Refet, Brian Sack, and Eric Swanson (2007). "Market-Based Measures of Monetary Policy Expectations," Journal of Business and Economic Statistics 25, 201-212.

Gürkaynak, Refet, Brian Sack, and Jonathan Wright (2007). "The U.S. Treasury Yield Curve: 1961 to the Present," Journal of Monetary Economics 54, 2291-2304.

Hanson, Samuel, and Jeremy Stein (2015). "Monetary Policy and Long-Term Real Rates," Journal of Financial Economics 115, 429-448. 
JORDÀ, ÒSCAR (2005). "Estimation and Inference of Impulse Responses by Local Projections," American Economic Review 95, 161-182.

Krishnamurthy, Arvind, And Annette Vissing-Jorgensen (2011). "The Effects of Quantitative Easing on Interest Rates: Channels and Implications for Policy," Brookings Papers on Economic Activity Fall, 215-265.

Krishnamurthy, Arvind, And Annette Vissing-Jorgensen (2013). "The Ins and Outs of LSAPs," in Global Dimensions of Unconventional Monetary Policy: Federal Reserve Bank of Kansas City Symposium Proceedings from Jackson Hole, Wyoming (Kansas City: Federal Reserve Bank of Kansas City) 57-111, available at http://www.kansascityfed.org/publications/research/escp.

Kuttner, Kenneth (2001). "Monetary Policy Surprises and Interest Rates: Evidence from the Fed Funds Futures Market," Journal of Monetary Economics 47, 523-544.

Nakamura, Emi, and Jon Steinsson (2018). "High-Frequency Identification of Monetary Non-Neutrality: The Information Effect," Quarterly Journal of Economics, forthcoming.

PAGAN, Adrian (1984). "Econometric Issues in the Analysis of Regressions with Generated Regressors," International Economic Review 25, 221-247.

Rogers, John, Chiara Scotti, and Jonathan Wright (2018). "Unconventional Monetary Policy and International Risk Premia," unpublished manuscript, Federal Reserve Board.

Summers, Lawrence (1991). "How Should Long-term Monetary Policy Be Determined?" Journal of Money, Credit, and Banking 23 (3) part 2, 625-631.

Swanson, Eric (2011). "Let's Twist Again: A High-Frequency Event-Study Analysis of Operation Twist and Its Implications for QE2," Brookings Papers on Economic Activity, Spring 2011, 151-188.

Swanson, ERIC (2017). "Measuring the Effects of Federal Reserve Forward Guidance and Asset Purchases on Financial Markets," NBER Working Paper 23311.

Swanson, Eric, And John Williams (2014). "Measuring the Effect of the Zero Lower Bound on Medium- and Longer-Term Interest Rates," American Economic Review 104, 3154-3185.

TaYlor, John (2012). "Fiscal Follies, Monetary Mischief" interview given to Barron's, April 12, 2012, by Gene Epstein.

The Wall Street Journal (2010). "Q\&A: IMF's Blanchard Thinks the Unthinkable," by Davis, Bob, February 11, 2010, Real Time Economics.

The Wall Street Journal (2013a). "Bond Markets Sell Off," by Burne, Katy, and Mike Chernev, June 19, 2013, Credit Markets.

The Wall Street Journal (2013b). "No Taper Shocks Wall Street: Fed 'Running Scared'," by Rusolillo, Steven, September 18, 2013, Money Beat.

The Wall Street Journal (2013c). "Fed Stays the Course on Easy Money," by Hilsenrath, Jon, and Victoria McGrane, September 19, 2013, Economy.

The Wall Street Journal (2014). "U.S. Stocks Surge after Fed Gets Dovish on Policy," by Vigna, Paul, December 17, 2014, Money Beat.

The Wall Street Journal (2015a). "U.S. Government Bonds Rally after Fed Statement," by Zeng, Min, March 18, 2015, Credit Markets.

The Wall Street Journal (2015b). "U.S. Stocks Surge as Fed Seen Taking Time on Rates," by WSJ Staff, March 18, 2015, Money Beat.

The Wall Street Journal (2015c). "Dollar Drops after Fed Keeps Interest Rates on Hold; U.S. Central Bank Leaves Interest Rates Unchanged," by Ira Iosebashvili, September 17, 2015.

The Wall Street Journal (2015d). "Rates: Lower, for Even Longer," by Justin Lahart, September 18, $2015, \mathrm{C} 1$. 
The Wall Street Journal (2015e). "Fed Delays Interest Rate Liftoff; Officials Still Expect to Move This Year, but Express Concerns About Global Tumult," by Jon Hilsenrath, September 17, 2015.

The Wall Street Journal (2015f). "U.S. Bond Yields Jump after Fed Fuels Rate-Increase Angst; Fed Signals It May Raise Rates before End of Year," by Min Zeng, October 28, 2015.

The Wall Street Journal (2015g). "Fed Keeps December Hike in Play," by Jon Hilsenrath, October 29, 2015.

Williams, John (2013). "Lessons from the Financial Crisis for Unconventional Monetary Policy," panel discussion at the NBER Conference on Lessons from the Financial Crisis for Monetary Policy, October 18, 2013, available at http://www.frbsf.org/our-district/press/presidents-speeches/williamsspeeches/2013/october/research-unconventional-monetary-policy-financial-crisis.

Woodford, Michael (2012). "Methods of Policy Accommodation at the Interest-Rate Lower Bound," in The Changing Policy Landscape: Federal Reserve Bank of Kansas City Symposium Proceedings from Jackson Hole, Wyoming (Kansas City: Federal Reserve Bank of Kansas City) 185-288, available at http://www.kansascityfed.org/publications/research/escp.

Wright, Jonathan (2012). "What Does Monetary Policy Do to Long-Term Interest Rates at the Zero Lower Bound?" Economic Journal 122, F447-F466. 